


\title{
SORTEANDO LOS INCONVENIENTES DEL ARTÍCULO 7 TUE: EL ADVENIMIENTO DEL CONTROL JURISDICCIONAL DEL ESTADO DE DERECHO
}

\author{
JOSÉ MANUEL CORTÉS MARTÍN ${ }^{1}$ \\ Universidad Pablo de Olavide \\ jimcormar@upo.es
}

Cómo citar/Citation

Cortés Martín, J. M. (2020).

Sorteando los inconvenientes del artículo 7 TUE: el advenimiento del control jurisdiccional del Estado de derecho.

Revista de Derecho Comunitario Europeo, 66, 473-517. doi: https://doi.org/10.18042/cepc/rdce.66.07

\section{Resumen}

La realidad de los últimos años refleja un creciente número de casos en los que algunos Gobiernos buscan conscientemente socavar sistemáticamente algunos de los valores claves de la Unión. Es entonces cuando nos hemos dado cuenta de las insuficiencias del art. 7 TUE para abordar los desafíos sistémicos contra estos valores, permitiendo un desafortunado impasse en el Consejo. Sin embargo, desde finales de 2017 una serie de fallos fundamentales han revelado la firme voluntad del TJUE para actuar como guardián de la ortodoxia del orden constitucional europeo para proteger, al menos, la independencia judicial en los Estados miembros. En este contexto, los procedimientos de infracción a través del procedimiento acelerado, acompañados de medidas cautelares de suspensión bajo apercibimiento de cuantiosas multas, han demostrado ser una forma efectiva de reaccionar ante esta crisis del Estado de derecho. También frente a la propia Unión el Tribunal de Justicia trata de hacer prevalecer los distintos perfiles del Estado de derecho, aunque en algunos ámbitos el balance es más bien tenue. Mientras que ello siga ocurriendo no cabe duda de que existe un contraste entre el control del respeto del Estado de derecho por parte de la propia Unión y la actitud opuesta frente a sus Estados miembros.

1 Catedrático de Derecho Internacional Público y Relaciones Internacionales en la Universidad Pablo de Olavide, de Sevilla. Todas las páginas web han sido consultadas por última vez el 26 de marzo de 2020. 


\title{
Palabras clave
}

Valores de la Unión; artículo 7 TUE; artículo 19 TUE; independencia judicial; Associação Sindical dos Juízes Portugueses; procedimientos de infracción contra Polonia y Hungría; jurisprudencia del TEDH sobre independencia judicial.

\section{DODGING THE DISADVANTAGES OF ARTICLE 7 TEU: THE ADVENT OF THE JURISDICTIONAL CONTROL OF THE RULE OF LAW}

\begin{abstract}
The reality of recent years has shown an increasing number of cases in which some governments are consciously seeking to undermine systematically Union's key values. It is then that we have become aware of the inadequacies of Art. 7 TEU to address systemic challenges against these values, allowing for an unfortunate impasse in the Council. However, since the end of 2017, a series of fundamental judgements have revealed the ECJ's firm will to act as guardian of the orthodoxy of the European constitutional order in order to protect at least judicial independence in the Member States. In this context, infringement procedures through the accelerated procedure and accompanied by the interim measure of suspension under the warning of large fines have proven to be an effective way of reacting to this crisis of the rule of law. Also before the Union itself, the Court of Justice tries to make prevail the different profiles of the rule of law, although in some areas the balance is unconvincing. As long as this continues, there is certainly a contrast between the Union's control of respect for the rule of law by itself and the opposite attitude towards its Member States.
\end{abstract}

\section{Keywords}

Union's values; Article 19 TEU; Article 7 TEU; judicial independence; Associação Sindical dos Juízes Portugueses; infringements procedures against Poland and Hungary; ECHR Case Law about judicial independence.

\section{EN SURMONTANT LES INCONVÉNIENTS DE L'ARTICLE 7 TUE: L'AVÈNEMENT DU CONTRÔLE JURIDICTIONNEL DE L'ÉTAT DE DROIT}

\section{Résumé}

La réalité des dernières années a montré un nombre croissant de cas dans lesquels certains gouvernements cherchent consciemment s'éloigner systématiquement des valeurs clés de l'Union. C'est alors quand nous avons pris conscience des insuffisances de l'art. 7 TUE pour relever les défis systémiques contre ces valeurs, permettant une impasse malheureuse au Conseil. Cependant, depuis la fin de 2017, une 
série d'arrêts fondamentaux ont révélé la ferme volonté de la CJUE d'agir en tant que gardienne de l'orthodoxie de l'ordre constitutionnel européen pour protéger au moins l'indépendance judiciaire des États membres. Dans ce contexte, les recours en manquement par le biais de la procédure accélérée, accompagnés d'une demande intérimaire de suspension et l'ordre de payer une astreinte élevée si la violation était constatée, se sont révélées comme un moyen efficace de réagir à cette crise de l'état de droit. Aussi devant l'Union elle-même, la Cour de justice s'efforce de faire prévaloir les différents profils de l'État de droit, même si dans certains domaines l'équilibre n'est que faible. Tant que cela continue, il ne fait aucun doute qu'il existe un contraste entre le contrôle exercé par l'Union sur le respect de l'État de droit par ses institutions et l'attitude opposée à l'égard de ses États membres.

\section{Mots clés}

Valeurs clés de l'Union; article 19 TUE; article 7 TUE; indépendance judiciaire; Associação Sindical dos Juízes Portugueses; procédures en manquement contre la Pologne et l'Hongrie; jurisprudence de la Cour EDH visant à garantir l'indépendance des juges. 


\section{SUMARIO}

I. INTRODUCCIÓN. II. LA CRISIS DEL ESTADO DE DERECHO Y EL IMPASSE POLÍTICO. III. EL ADVENIMIENTO DEL CONTROL JURISDICCIONAL: 1. Judicial Serendipity: el artículo 19 TUE como concreción del Estado de derecho. 2. La salvaguarda del Estado de derecho a través del procedimiento de infracción. 3. El control jurisdiccional horizontal. 4. La defensa del Estado de derecho desde Estrasburgo. IV. LOS RESULTADOS. V. EL RESPETO DEL ESTADO DE DERECHO POR LA PROPIA UNIÓN: i̇UNA CRITICABLE ASIMETRÍA? VI. CONCLUSIONES. BIBLIOGRAFIA.

\section{INTRODUCCIÓN}

Como un valor sobre el cual se funda explícitamente la Unión y que se dice «común a los Estados miembros» de conformidad con el art. 2 TUE, el Estado de derecho forma parte de la esencia de su ordenamiento jurídico, habiendo proporcionado históricamente el elemento articulador que ha mantenido unido todo el edificio político y jurídico de esta organización internacional. Aunque tuvo una incorporación tardía a las disposiciones de los Tratados, el concepto ya estaba inmerso en el orden jurídico comunitario desde sus inicios ${ }^{2}$ vía tradiciones constitucionales comunes y en los últimos tiempos ha sido objeto de una profundización en el contexto de la política de ampliación para garantizar que todos los Estados candidatos cumplen las condiciones sustantivas del art. 49(1) TUE.

Como en la mayoría de las áreas del derecho constitucional de la Unión, el Tribunal de Justicia desarrolla un papel fundamental en la aclaración del contenido del art. 2 TUE. Dada la función que tiene encomendada, definida en el art. 19 TUE e informada por los objetivos del art. 13(1) TUE, es lógico esperar que vaya codificando progresivamente el contenido de estos valores, al igual que hiciera con el acervo de principios generales del derecho, incluso en ausencia de fundamentos sustantivos en el derecho originario o con el contenido de las disposiciones de la Carta, que en parte encuentran sus raíces en estos principios generales.

Teniendo en cuenta, además, la aplicación descentralizada del derecho de la Unión y, en particular, el art. 19 TUE, que confía a los órganos jurisdiccionales

2 Sobre la evolución, puede verse, entre otros, Liñán Nogueras (2018). 
nacionales y al Tribunal de Justicia la tarea de garantizar la plena aplicación del Derecho de la Unión y la tutela judicial que ese ordenamiento jurídico confiere a los justiciables ${ }^{3}$, los tribunales nacionales también han desempeñado un papel fundamental en la defensa del Estado de derecho. En cooperación con el Tribunal de Justicia, han proporcionado recursos efectivos para proteger los derechos que ese ordenamiento confiere a los particulares, incluso cuando la legislación nacional lo impedía ${ }^{4}$; han consolidado la primacía, dejando sin aplicación normas nacionales contradictorias, incluso de rango constitucional ${ }^{5}$, y han otorgado medidas cautelares, incluso cuando la legislación nacional no las permitía ${ }^{6}$. Al proporcionar dicha protección jurisdiccional, los tribunales nacionales pueden entablar un diálogo con el Tribunal de Justicia, siendo la cuestión prejudicial la piedra angular de esta cooperación ${ }^{7}$. Sin embargo, este mecanismo de cooperación solo es concebible entre tribunales que gocen de independencia, de la cual el Tribunal también se ha ocupado, ya sea desde su perspectiva formal, en cuanto a los órganos que pueden plantear dichas cuestiones prejudiciales ${ }^{8}$, como también material9 ${ }^{9}$. Es cierto, sin embargo, que este último aspecto nunca representó una verdadera preocupación puesto que al derivarse la independencia judicial de las tradiciones constitucionales

3 Sentencia de 24 de junio de 2019, Comisión/Polonia (Independencia del Tribunal Supremo), C-619/18, EU:C:2019:531, apdo. 47; Dictamen 1/09, Tribunal europeo y comunitario de patentes, EU:C:2011:123, apdo. 66; Sentencia de 28 de abril de 2015, T \& L Sugars y Sidul Açúcares/Comisión, C-456/13 P, EU:C:2015:284, apdo. 45.

4 Entre otras, Sentencia de 15 de mayo de 1986, Johnston, 222/84, EU:C:1986:206.

5 Entre otras, Sentencia de 8 de septiembre de 2010, Winner Wetten, C-409/06, EU:C:2010:503, apdo. 61.

6 Sentencias de 19 de junio de 1990, Factortame I, C-213/89, EU:C:1990:257; de 9 de marzo de 1978, Simmenthal, 106/77, EU:C:1978:49; de 5 de marzo de 1996, Brasserie du Pêcheur y Factortame III, C-46 y 48/93, EU:C:1996:79.

7 Dictamen 2/13 (Adhesión de la Unión al CEDH), EU:C:2014:2454, apdo. 176; Sentencia de 6 de marzo de 2018, Achmea, C-284/16, EU:C:2018:158, apdo. 37.

8 Por ejemplo, basándose en su renovada doctrina sobre la independencia judicial, el Tribunal acaba de rechazar que el Tribunal Económico Administrativo Central pueda plantear cuestiones prejudiciales, Sentencia de 21 de enero de 2020, Banco de Santander, C-274/14, EU:C:2020:17.

9 Sentencias de 19 de septiembre de 2006, Wilson, C-506/04, EU:C:2006:587; de 6 de noviembre de 2012, Comisión / Hungría, C286/12, EU:C:2012:687; de 8 de abril de 2014, Comisión/Hungría, C-288/12, EU:C:2014:237; de 9 de marzo de 2010, Comisión/Alemania, C-518/07, EU:C:2010:125; de 2 de junio de 2016, Comisión/ Portugal, C-205/14, EU:C:2016:393; así como los fallos que veremos más adelante frente a Polonia. 
siempre fue percibida como un dato incuestionable. Como mostraremos a lo largo de este trabajo, la realidad de los últimos años ha venido, sin embargo, a alterar este axioma.

No cabe duda, por tanto, de que el Estado de derecho siempre estuvo inmerso en el proceso de construcción europea y nunca hicieron falta mecanismos para su defensa, siendo exagerado afirmar, como hacen algunos, que no exista un acervo sobre los valores y que la Unión sea incapaz de definir su contenido ${ }^{10}$. Aunque el art. 2 TUE no desempeñó un papel central en la jurisprudencia del TJUE durante algún tiempo ${ }^{11}$, comenzó a aparecer con cierta asiduidad a partir de $2014^{12}$ y se ha consolidado a partir de todos los fallos contra Polonia que veremos a lo largo de este trabajo. En realidad, la inserción del art. 7 en la versión del TUE aprobada en Ámsterdam reveló más bien una falta de confianza sobre la efectividad de la condicionalidad de preadhesión en un momento en que la Unión se estaba preparando para recibir a diez nuevos países de Europa del Este, idéntico motivo que llevó a la Asamblea Parlamentaria del Consejo de Europa a introducir el mecanismo Post Accession Monitoring $^{13}$ o a la Comisión a instaurar el Mecanismo de Cooperación y Verificación cuando Rumanía y Bulgaria se incorporaron a la Unión en $2007^{14}$.

10 La noción ambigua de «valores», su vaguedad y la jurisdicción limitada del TJUE en virtud del art. 269 del TFUE llevaron a muchos a dudar de si el art. 2 TUE gozaba de verdaderos efectos jurídicos capaces de ser objeto de control judicial, Kochenov (2015: 88); Levits (2018: 521); Müller (2015: 141).

11 El TJUE fue interrogado sobre el contenido del art. 2 TUE, por ejemplo, en el asunto C-505/13 Levent Redzheb Yumer, EU:C:2014:2129; aunque rechazó responder, no por carecer de competencia, sino porque el juez a quo no había explicado la relevancia de esta disposición para su litigio. En el asunto C-146/13 España/Parlamento y Consejo, UE:C:2015:298, nuestro país también lo invocó, aunque sin éxito; véanse las Conclusiones del abogado general Bot en este asunto, EU:C:2014:2380, puntos 35-38. En la doctrina, puede verse, por ejemplo, Nicolosi (2015).

12 Dictamen n..$^{\circ}$ 2/13, apdo. 168; sentencias de 27 de febrero de 2018, Asociación Sindical de Jueces Portugueses, C-64/16, EU:C:2018:117, apdos. 30-32; Sentencia Achmea, apdo. 34; de 25 de julio de 2018, Minister for Justice and Equality (LM), C-216/18 PPU, EU:C:2018:586; apdos. 35, 48 y 50; y de 10 de diciembre de 2018, Wightman, C-621/18, EU:C:2018:999, apdos. 62-63.

13 Y que fue activado frente a Polonia el pasado 28 de enero de 2020, https://bit. ly/30StM0J.

14 Cuando se incorporaron en 2007, Rumanía y Bulgaria aún debían emprender reformas en el ámbito judicial y de lucha contra la corrupción. Para ayudarles a subsanar esas deficiencias, la Comisión creó como medida transitoria este Mecanismo, cuyos 
Los negociadores del Tratado de Ámsterdam probablemente esperaban que la mera presencia del art. 7 TUE actuaría como un elemento disuasorio suficiente que evitara cualquier retroceso democrático. Sin embargo, los hechos han venido demostrando desde hace años signos de debilitamiento hasta alcanzar una situación crítica. Ha sido en ese momento cuando nos hemos dado cuenta de las graves insuficiencias del mecanismo de sanción del art. 7 TUE, derivadas fundamentalmente de la discrecionalidad política involucrada en dicho procedimiento, los altos umbrales requeridos y, en especial, la falta de verdadero coraje político; todo lo cual está permitiendo un desafortunado impasse en el Consejo. Como en otras áreas, ha sido la jurisprudencia del TJUE donde podemos encontrar una verdadera salvaguarda del Estado de derecho. En los párrafos siguientes, el análisis se centrará en las interconexiones que surgen entre los instrumentos de protección del Estado de derecho, destacando la complementariedad que caracteriza los objetivos perseguidos por la jurisdiccionalización de esta protección, que como reacción al impasse político en el Consejo en los últimos tiempos ha venido siendo desarrollada por el TJUE en cooperación con los jueces naturales del derecho de la Unión. Finalmente, nos plantearemos si existe un control jurisdiccional de semejante magnitud sobre el respeto de este valor por la propia Unión y, en caso contrario, hasta qué punto esta diferencia no constituye una criticable asimetría.

\section{LA CRISIS DEL ESTADO DE DERECHO Y EL IMPASSE POLÍTICO}

La realidad de los últimos años ha demostrado un creciente número de casos en los que las autoridades nacionales buscan conscientemente socavar sistemáticamente los valores claves de la Unión. Pueden recordarse en este sentido los rasgos xenófobos del Gobierno presidido por Jörg Haider en Austria en el año 2000 (Sadurski, 2009: 385); la polémica expulsión de gitanos búlgaros y rumanos de Francia en 2010; la deriva autoritaria del primer Ministro húngaro, Viktor Orbán, entre 2011 y 2012, para restringir la inamovilidad judicial al anticipar la jubilación de un gran número de jueces

progresos han sido escasos; véase COM (2019)498 y COM (2019)393, de 22 de octubre de 2019. En los asuntos C-83/19, C-127/19, C-195/19, C-291/19, C-355/19 y C-397/19, Forumul Judecătorilor Din România y otros; una serie de cuestiones prejudiciales plantean al TJUE si en virtud de los informes derivados de este Mecanismo o de los arts. 2 y 19 TUE se deduce que Rumanía infringe la independencia judicial al nombrar el Gobierno de forma discrecional la dirección de la inspección judicial. 
y fiscales; la crisis constitucional de Rumanía entre 2012 y 2013 cuando el Gobierno se negó a acatar los fallos de su propio Tribunal Supremo, culminando con las derivas autoritarias de Hungría y Polonia, las cuales han seguido una inexorable evolución hasta provocar el desencadenamiento de la fase preventiva del art. 7.1 TUE frente a estos dos países, al tiempo que los recientes acontecimientos en Rumanía y Bulgaria son igualmente percibidos con especial preocupación.

Es entonces cuando nos hemos dado cuenta de las insuficiencias del art. 7 TUE para abordar los desafíos sistémicos percibidos en esos Estados miembros. Estas dificultades, junto con el limitado alcance de los procedimientos de infracción que la Comisión creía que podía iniciar, fueron las razones que llevaron a esta institución primero ${ }^{15}$ y después el Parlamento ${ }^{16}$ y el Consejo ${ }^{17}$, a crear mecanismos preventivos y alternativos, que tienen en común su fundamento dialógico con el Estado miembro afectado y, lo que es peor, su constatada ausencia de resultados en la práctica. Esta deriva desencadenó que la Comisión se dirigiera formalmente al Consejo en 2017 para pedirle que constatara un riesgo de violación del Estado de derecho frente a Polonia, que en esos momentos proyectaba una delicada reforma del poder judicial que cuestionaba la independencia de los jueces ${ }^{18}$. Y lo mismo hizo el Parlamento unos meses después frente a Hungría por las amenazas sobre la independencia de los jueces, la libertad de expresión, la corrupción, los derechos de las minorías y la situación de los inmigrantes y refugiados ${ }^{19}$. Sin embargo, incluso si ambas iniciativas para activar la vertiente preventiva del art. 7.1 TUE demuestran sobradas evidencias de fallos sistémicos en el respeto de uno u otro componente del Estado de derecho, la falta de verdadero coraje político ha impedido hasta ahora que el Consejo adopte decisión alguna,

15 COM (2014)158, final, de 11 de marzo de 2014.

16 Para tratar de controlar el respeto de los valores del art. 2 TUE, el 25 de octubre de 2016 el Parlamento recomendó la creación un nuevo mecanismo en forma de acuerdo interinstitucional, doc. 2015/2254(INL).

17 Además de su papel institucional claramente definido en el art. 7 TUE, el Consejo ha desarrollado cada año un diálogo sobre el Estado de derecho en el seno de su formación de asuntos generales, véanse sus conclusiones adoptadas el 16 de diciembre de 2014, https://bit.ly/3ebhQLi, pp. 20-21.

18 COM (2017) 835 final, de 20 de diciembre de 2017.

19 Doc. 2017/2131(INL). Esta resolución ha sido impugnada judicialmente por este país, C-650/18 Hungría/Parlamento Europeo, pendiente, al considerar que en la votación el Parlamento infringió gravemente lo dispuesto en el art. 354 TFUE y en su propio Reglamento interno. 
permaneciendo el procedimiento a nivel de anodinas audiencias con los países afectados.

Este impasse político en el Consejo se ha traducido, además, en una cierta resistencia burocrática frente a la Comisión y al Parlamento en todo lo relacionado con el respeto de este valor de la Unión. Frente a la Comisión, esta impresión se deduce de varios dictámenes del Servicio Jurídico del Consejo sobre algunas iniciativas presentadas para presionar a los Estados miembros a salvaguardar su respeto. Así, con respecto a la propuesta de creación en 2014 del mecanismo preventivo denominado Marco del Estado de Derecho, un desconcertante dictamen de este Servicio Jurídico rechazó con escaso fundamento que esta propuesta fuera compatible con el principio de atribución, al no existir ninguna base jurídica en los Tratados, al margen del art. 7 TUE, que faculte a las instituciones para crear un nuevo mecanismo de supervisión; deduciendo que solo los Estados miembros, y ni siquiera el Consejo, podían desarrollar esta iniciativa mediante un acuerdo intergubernamental ${ }^{20}$. Es curioso observar que este dictamen ni siquiera citaba el art. 292 TFUE, que establece claramente la competencia de la Comisión para adoptar recomendaciones; ni tampoco el art. 13.1 TUE, en cuya virtud el marco institucional tiene como finalidad promover sus valores. Además, parece obvio que el art. 7 TUE ya faculta implícitamente a la Comisión para investigar y eventualmente recomendar contra cualquier riesgo potencial de una violación grave de los valores de la Unión. Sea como fuere, la cuestión perdió relevancia no solo porque la Comisión, a pesar de este dictamen, puso en marcha este mecanismo para abordar el caso polaco sin que encontrara oposición ni del país afectado ni del Consejo, institución que aprovechó para crear su propio mecanismo intergubernamental de supervisión ${ }^{21}$, sino especialmente porque ni el mecanismo propuesto por la Comisión (Blázquez Peinado, 2019: 31), ni la supervisión desarrollada por el Consejo han dado ningún resultado en la práctica (Uitz, 2019).

La impresión de resistencia burocrática se vio asimismo corroborada frente a otra nueva propuesta de la Comisión, esta vez para crear en el marco financiero plurianual una condicionalidad basada en el respeto del Estado de

20 Dictamen del Servicio Jurídico del Consejo de 14 de mayo de 2014, n. ${ }^{\circ}$ 10296/14, https://bit.ly/2N5sp6M, apdo. 28. Este dictamen fue objeto de fuertes críticas, véase, entre otros, Baratta (2016), Besselink (2017), Kochenov y Pech (2015), Oliver y Stefanelli (2016); mientras que fue apoyado por escasos autores: Lazzerini (2016), Di Federico (2015).

21 Supra, nota 17. 
derecho ${ }^{22}$. Se trata de una iniciativa importante porque Polonia y Hungría son los mayores beneficiarios per cápita de los fondos europeos. Si tomamos el ejemplo de Polonia, se le han asignado un total de 86.000 millones de euros de varios fondos para el período 2014-2020 y en circunstancias normales sería receptor de una cifra similar en las próximas perspectivas financieras. De ahí que el debate se haya centrado en los últimos tiempos en cómo detener el flujo de fondos para que al menos este dinero no sea utilizado para socavar los valores de la Unión. Con este objetivo, la propuesta permitiría suspender la concesión de fondos a un Estado miembro por considerar que adolece de un fallo sistémico en el respeto del Estado de derecho. Ha recibido un apoyo mayoritario, tanto dentro del marco institucional ${ }^{23}$, especialmente por el Parlamento, que primero alentó su presentación ${ }^{24}$ y luego la aprobó en primera lectura $^{25}$, como a nivel doctrinal (Butler, 2018; Halmai, 2018; Kelemen y Scheppele, 2018; Heinemann, 2018; Pérez Bernárdez, 2019; Scheppele et al., 2018). Sin embargo, fue rechazado nuevamente por el Servicio Jurídico del Consejo a través de un dictamen hecho público de manera parcial, que reitera el argumento del art. 7 TUE como lex specialis, siendo el único mecanismo disponible en virtud de los Tratados para hacer cumplir los valores del art. 2 TUE $^{26}$.

Si recordamos el asunto del bosque de Białowieska sobre la Directiva Hábitats, en el que el TJUE impuso a Polonia como medida cautelar una multa para garantizar la aplicación efectiva del erecho de la Unión, afirmando explícitamente que dicha aplicación era un componente esencial del Estado de derecho ${ }^{27}$, alcanzaremos la conclusión de que el art. 7 TUE no es el único mecanismo disponible en virtud de los Tratados para hacer cumplir los valores del art. 2 TUE. Lo mismo cabe deducir del asunto Minister for Justice and

22 COM (2018) 324 final, de 2 de mayo de 2018.

23 Dictamen del Comité Económico y Social n. ${ }^{\circ}$ EESC 2018/02955, DO n. ${ }^{\circ}$ C 62 de 15 de febrero de 2019; Dictamen del Comité de las Regiones de 9 de octubre de 2018, DO n. ${ }^{\circ}$ C 461/70, de 21 de diciembre de 2018; Dictamen del Tribunal de Cuentas n. ${ }^{\circ}$ 1/2018, DO n. ${ }^{\circ} \mathrm{C} 291$, de 17 de agosto de 2018.

24 Resolución de 28 de febrero de 2018 sobre el próximo programa financiero plurianual, n. ${ }^{\circ}$ A8-0048/2018.

25 Resolución de 4 de abril de 2019, sobre la propuesta de Reglamento relativa a la protección del presupuesto de la Unión en caso de deficiencias generalizadas del Estado de Derecho en los Estados miembros, n. ${ }^{\text {T }}$ TA/2019/0349.

26 Dictamen del Servicio Jurídico del Consejo de 25 de octubre de 2018, doc. n. ${ }^{\circ}$ $13593 / 18$.

27 Auto de 20 de noviembre de 2017, Comisión/Polonia (Bosque de Białowieża), C-441/17 R, EU:C:2017:877, apdo. 102. 
Equality $(L M)^{28}$, donde el TJUE le dijo al juez de remisión que debía evitar entregar una persona a otro Estado miembro si tras una valoración general y concreta alcanzaba la conclusión de que el contenido esencial del derecho del procesado a un juicio con todas las garantías, tal como se deriva del art. 2 TUE, corría el riesgo de una violación sustancial, de lo que cabe deducir que este fallo faculta a todos los jueces para defender los valores de la Unión haciendo excepciones a la obligación general de reconocimiento mutuo establecida en el derecho derivado. Finalmente, la saga judicial polaca, que abordaremos más adelante, también demuestra que el art. 7 TUE no es el único mecanismo disponible para lograr el respeto del Estado de derecho en los Estados miembros, constituyendo el art. 19(1) TUE, párr. 2, una garantía para proteger, al menos, la independencia judicial. Todos estos argumentos parecen demostrar suficientemente que el art. 7 TUE no es el único mecanismo disponible en virtud de los Tratados para hacer cumplir los valores del art. 2 TUE.

Por consiguiente, parece claro que la Unión puede utilizar su presupuesto para alcanzar sus objetivos. De hecho, los fondos estructurales y el fondo de cohesión se encuentran en la actualidad vinculados al cumplimiento de condicionalidades macroeconómicas, en particular al pacto de estabilidad y crecimiento. El límite se encontraría en el respeto del principio de atribución, sin que un objetivo general implique necesariamente la existencia de una competencia como señala explícitamente la Declaración n. ${ }^{\circ} 41$ anexa a los Tratados. La Comisión ha demostrado ser consciente de este problema, al elegir para fundamentar su propuesta una base jurídica precisa como es el art. 322, párr. 1, a) TFUE, que faculta al Parlamento y al Consejo para adoptar mediante reglamentos «las normas financieras por las que se determinarán, en particular, las modalidades de establecimiento y ejecución del presupuesto, así como las referentes a la rendición y censura de cuentas». Esta disposición permite sortear el problema competencial, al enmarcar dicha propuesta sobre el vínculo entre la existencia de deficiencias generalizadas sobre el Estado de derecho en un Estado miembro y la necesidad de proteger los intereses financieros de la Unión, garantizando un vínculo suficientemente directo con el gasto $^{29}$.

28 Sentencia de 25 de julio de 2018, Minister for Justice and Equality (LM), EU:C:2018:586.

29 Aunque las condiciones generales requeridas para activar el mecanismo deberían reemplazarse por un conjunto de fundamentos claros, precisos y objetivos con un vínculo directo suficiente con el gasto de la Unión, De la Rosa (2019); Fisicaro (2019); Vita (2018); Dictamen n. ${ }^{\circ}$ 1/2018 del Tribunal de Cuentas. 
Es cierto, sin embargo, que el análisis se torna más incierto si realizamos una proyección del art. 7.3 TUE, en virtud del cual, al proceder a dicha suspensión (de los votos del Estado miembro sancionado), el Consejo debe tener en cuenta las posibles consecuencias para los derechos y obligaciones de las personas físicas y jurídicas, de lo que quizás podría deducirse que cualquier sanción, y no solo las del art. 7 TUE, podría afectar a estos derechos, siendo bastante probable que la suspensión de fondos europeos rebase este umbral. Desde esta perspectiva, no es descabellado considerar este mecanismo como una forma de eludir los estrictos requisitos sustantivos y procedimentales del art. 7 TUE para imponer sanciones contra los Estados miembros recalcitrantes y de ahí que algún autor estime que difícilmente puede conciliarse con el derecho originario (Rangel de Mesquita, 2018). O bien, si analizamos su oportunidad desde el punto de vista político, dado que cualquier Gobierno autocrático podría explotar a su favor esta suspensión de fondos, criticándola como el intento de una coalición internacional de despojar a los países menos desarrollados, y por ende a sus ciudadanos, de las ayudas diseñadas para compensar sus desventajas competitivas en el Mercado Interior (Adamski, 2019: 649; Steinbeis, 2017), pudiendo conducir a una reacción popular en apoyo de dicho Gobierno autocrático, lo cual, más que socavar, podría reforzar su capacidad para aplicar políticas internas represivas (Editorial, 2016: 601-603). Todo ello quiere decir que no son pocos los desafíos que acompañan a esta propuesta, aunque ninguno de ellos parece insuperable.

Finalmente, la impresión de resistencia burocrática por parte del Consejo en todo lo relacionado con el respeto del Estado de derecho se deduce de la postergación del Parlamento en las audiencias de Hungría en el marco del art. 7.1 TUE, pese a haber sido la institución que impulsó formalmente el procedimiento frente a este país ${ }^{30}$. Así se deduce del primer conjunto de normas procedimentales que rigen estas audiencias, adoptadas por el Consejo en julio de $2019^{31}$, sobre la base de un nuevo dictamen de su Servicio Jurídico, esta vez oral y confidencial, cuya divulgación acaba de ser exigida judicialmente ${ }^{32}$. Sobre la base del principio de equilibrio institucional, este dictamen rechaza que la Eurocámara pueda asistir a estas audiencias (Pech et al., 2019). Cabe recordar, sin embargo, que en el caso de Polonia no solo permitió la asistencia

30 Véanse las críticas del Parlamento en su Resolución de 16 de enero de 2020 sobre las audiencias en curso en virtud del artículo 7.1 TUE relativas a Polonia y Hungría (2020/2513(RSP).

31 Standard modalities for hearings referred to in Article 7(1) TEU, https://bit.ly/3edXocS.

32 T-252/19, Pech/Consejo, pendiente. 
de la Comisión como institución impulsora del procedimiento, sino que la invitó a presentar varios informes sobre el estado de la cuestión. Este trato diferenciado entre las instituciones activadoras del art. 7 TUE parece contradecir, más que justificar, el principio de equilibrio institucional, desviándose de las premisas básicas de la igualdad procesal interinstitucional, un principio suficientemente importante en la jurisprudencia del TJUE, reafirmado incluso frente al silencio de los Tratados, como fue el caso ante la falta de legitimación del Parlamento en el marco del recurso de anulación. Recordemos en este sentido el asunto Chernobyl, en el que el Tribunal enfatizó que el respeto de este principio implicaba que cada una de las instituciones debía poder ejercer sus competencias sin invadir las de las demás ${ }^{33}$. Esta exclusión también parece problemática desde la perspectiva del principio de cooperación leal, cuya extensión interinstitucional ha sido confirmada por el Tratado de Lisboa. Según la jurisprudencia, este principio debe aplicarse incluso ante el silencio de los Tratados y en todas las acciones de las instituciones, de lo que podría deducirse que impediría al Consejo tratar de manera diferente y menos favorable al Parlamento. Desde una perspectiva más general, no deja de ser paradójico que se organicen unas audiencias para presionar a un determinado Estado miembro a respetar el Estado de derecho y se incumpla de forma tan flagrante en sede interna.

\section{EL ADVENIMIENTO DEL CONTROL JURISDICCIONAL}

Si pensamos en las posibles hipótesis para colmar la fragilidad intrínseca del control político del Estado de derecho, la primera solución imaginable es el desencadenamiento del procedimiento de infracción del art. 258 TFUE, cuyas ventajas son indudables al no someterse a los obstáculos políticos del art. 7 TUE. Teniendo en cuenta que los Tratados no reglamentan las relaciones entre ambas disposiciones y que las dos pueden contribuir técnicamente a salvaguardar las obligaciones de los Estados miembros derivadas del art. 2 TUE, podría pensarse que uno u otro constituyen medios complementarios para salvaguardar los valores del art. $2 \mathrm{TUE}^{34}$ y de ahí que la doctrina mayoritaria haya venido exigiendo a la Comisión activar el procedimiento

33 Sentencia de 22 de mayo de 1990, Parlamento/Consejo, C-70/88, EU:C:1990:217, apdo. 22.

34 Véanse en este sentido las Conclusiones del abogado general Tanchev en el asunto C-619/18, Comisión/Polonia (Independencia del Tribunal Supremo), EU:C:2019: 325 , punto 50 . 
de infracción para salvaguardar los valores (Bárd y Śledzińska-Simon, 2019; Kochenov y Pech, 2016: 1065; Hillion, 2016; Kochenov, 2017; Dawson et al., 2014: 116; Scheppele, 2016; Schmidt y Bogdanowicz, 2018). Sin embargo, la deliberada inclusión de la unanimidad en el segundo apartado del art. 7 TUE demuestra el deseo de establecer un umbral elevado para la adopción de sanciones. Teniendo en cuenta, además, que el art. 269 TFUE asigna al TJUE competencias limitadas en relación con el art. 7 TUE, reduciendo su papel a la salvaguarda de los requisitos procesales, pero no a las determinaciones sustantivas de las instituciones políticas, era verdaderamente dudoso hasta dónde podía y debía llegar realmente el procedimiento jurisdiccional puesto que una intervención más sólida haría del Tribunal el flanco de la crítica al interferir en las competencias retenidas por los Estados miembros o atribuidas al Consejo y al Consejo Europeo ${ }^{35}$. Algunos de estos argumentos han sido alegados por los defensores del carácter de lex specialis del art. 7 TUE, deduciendo la inaplicabilidad del procedimiento de infracción para denunciar las violaciones del art. 2 TUE, máxime teniendo en cuenta la gran variedad y vaguedad de los valores allí especificados, lo cual podría hacer dudar de su capacidad para crear obligaciones a cargo de los Estados miembros. Así parecía deducirse del asunto Giménez Zaera ${ }^{36}$, donde el Tribunal afirmó que un objetivo inspirador de la creación de la entonces Comunidad (en este caso se trataba de la elevación acelerada del nivel de vida), por su generalidad, no podía tener por efecto crear obligaciones jurídicas a cargo de los Estados miembros, ni derechos en favor de los particulares. Todos estos condicionantes hicieron que la Comisión albergara durante años una interpretación limitada de sus competencias, según la cual fuera del alcance estricto del derecho de la Unión no podía utilizar el procedimiento de infracción de manera efectiva cuando algún Estado miembro viole los valores, por cuanto aquellos son de naturaleza política y difusa, no susceptibles de revisión mediante este procedimiento; con lo cual, en ausencia de una competencia legislativa general sobre la organización del poder judicial a nivel nacional o sobre los estándares de los sistemas de educación superior, los ataques gubernamentales a la organización judicial o contra las universidades difícilmente podían perseguirse, según esta institución, mediante el procedimiento de infracción, ejercitándolo

35 De ahí que algunos autores hayan sugerido que el Tribunal debe adquirir nuevas competencias en este ámbito y reemplazar de facto los mecanismos políticos creados por los Tratados, por ejemplo Scheppele (2016), mientras que otros parecen mostrarse más partidarios de postergar la vía judicial: Von Bogdandy (2019).

36 Sentencia de 29 de septiembre de 1987, Giménez Zaera, 126/86, EU:C:1987:395, apdo. 11 . 
únicamente frente a infracciones singulares donde las autoridades nacionales dejaran de implementar o aplicaran incorrectamente disposiciones específicas del derecho de la Unión ${ }^{37}$, enfoque defendido por algunos autores (Avbelj, 2013; Gormley, 2017: 78; Editorial, 2015: 625).

Esto explica por qué hasta el fallo del TJUE en el asunto Asociación Sindical de Jueces Portugueses la Comisión buscó proteger la independencia judicial en Hungría a través de un recurso por incumplimiento basado en la discriminación por edad ${ }^{38}$; o que en el contexto de los intentos del presidente húngaro por cerrar la Universidad Central Europea (Bárd, 2017; Halmai, 2017), eligiera de manera similar una ruta indirecta para proteger la libertad académica a través de un recurso basado principalmente en la violación de las libertades de establecimiento y de servicios ${ }^{39}$; o que eligiera la conculcación de la libre circulación de capitales y el derecho a la libertad de asociación en el marco del recurso contra Hungría por la Ley sobre la Transparencia de las Organizaciones No Gubernamentales ${ }^{40}$. Todos estos recursos omitían la razón por la cual estas prácticas eran profundamente perturbadoras para el Estado de derecho. Sin embargo, desde finales de 2017 una serie de fallos fundamentales revelaron la firme voluntad del TJUE de actuar como guardián de la ortodoxia del orden constitucional europeo.

\section{JUDICIAL SERENDIPITY: EL ARTÍCULO 19 TUE COMO CONCRECIÓN DEL ESTADO DE DERECHO}

Intentando defender sus salarios de las medidas de austeridad, un grupo de jueces portugueses brindó la oportunidad al TJUE para encontrar una forma de salvaguardar judicialmente el Estado de derecho y la independencia del poder judicial en toda la Unión (Bonelli y Claes, 2018), permitiendo esquivar el impasse político y sortear los problemas derivados de la invocación del art. $47 \mathrm{CDF}$ debido a su art. 51(1). En efecto, de forma inesperada el Tribunal decidió en el asunto Asociación Sindical de Jueces Portugueses que

37 COM (2014)158, final, de 11 de marzo de 2014, p. 5.

38 Supra, nota 9.

39 Recurso interpuesto el 1 de febrero de 2018, Comisión /Hungría, C-66/18.

40 Sentencia de 18 de junio de 2020, Comisión/Hungría, C-78/18, EU:C:2020:476. El fallo sigue las conclusiones del abogado general Sánchez-Bordona, presentadas el 14 de enero de 2020, en las que expuso un nuevo estándar de revisión cuando la infracción de una libertad va unida a una infracción de la CDF y propuso de forma concreta que la reglamentación húngara restringe indebidamente la libre circulación de capitales e implica una injerencia injustificada en el respeto de la vida privada, la protección de los datos de carácter personal y la libertad de asociación, EU:C:2020:1. 
el segundo párrafo del art. 19 TUE, apartado 1, debía interpretarse no como una disposición meramente procesal, como había defendido el Abogado General Saugmandsgaard en sus Conclusiones en este asunto, sino abarcando, en conjunción con el art. 2 TUE, un elemento sustantivo como puede ser la independencia e imparcialidad de los jueces. Por consiguiente, dicha disposición es una concreción del valor Estado de derecho del art. $2 \mathrm{TUE}^{41} \mathrm{y}$, por lo tanto, un instrumento para su operatividad. Así fue cómo un asunto que inicialmente versaba sobre la revisión judicial de medidas de austeridad y la aplicabilidad de la Carta fue transformado sorpresivamente en una decisión sobre la organización del sistema judicial europeo y el respeto del Estado de derecho.

Es cierto, sin embargo, que para alcanzar este resultado tuvo que sortear varios desafíos que le exigieron una gran dosis de creatividad. En primer lugar, declaró la admisibilidad del asunto, a pesar de que había evitado hacerlo en asuntos anteriores también relacionados con medidas de austeridad derivadas del MEDE. En segundo lugar, al asumir jurisdicción debía evitar un debate detallado sobre el alcance del art. $47 \mathrm{CDF}$, algo crucial porque las medidas más controvertidas adoptadas en Polonia, Hungría o Rumanía no parecen constituir una ejecución del derecho de la Unión. Pero al sortear la Carta, tenía que encontrar un fundamento alternativo en los Tratados sobre el que basar el principio de independencia judicial, hallándolo en el art. 19.1 TUE, párr. 2. Así, el mero hecho de ser un tribunal con jurisdicción para decidir potencialmente sobre la interpretación o aplicación del derecho de la Unión es suficiente para entrar en el ámbito material de esta disposición ${ }^{42}$.

Es probable que con dicha transformación el Tribunal persiguiera dos objetivos principales: en primer lugar, adquirir un papel relevante en el debate sobre el respeto del Estado de derecho frente a la inactividad del Consejo, de lo que ya vimos un mensaje implícito en el asunto del bosque de Białowieza, rechazando un papel marginal en uno de los debates constitucionales más relevantes de los últimos tiempos; y en segundo lugar y de forma más general, dejar claro que la organización de los poderes judiciales nacionales no es una cuestión puramente doméstica.

A partir de este fallo, el art. 19.1 TUE, párr. 2, se ha convertido en fuente de obligaciones con respecto a la independencia judicial, abriendo la posibilidad de que la Comisión articule el procedimiento de infracción sobre este fundamento, en combinación con el art. 2 TUE, contra todo Estado miembro que adopte medidas capaces de hacer peligrar la garantía de una protección

41 Sentencia Asociación Sindical de Jueces Portugueses, apdo. 32.

42 Ibid., apdo. 25. 
judicial efectiva, comprometiendo el funcionamiento del sistema judicial de la Unión; sin que sea necesario demostrar que dichas medidas suponen una ejecución del Derecho de la Unión ${ }^{43}$. Y también representaba un incentivo para que los tribunales nacionales presentaran nuevas cuestiones prejudiciales que pudieran contribuir a garantizar la independencia judicial.

\section{LA SALVAGUARDA DEL ESTADO DE DERECHO A TRAVÉS DEL PROCEDIMIENTO DE INFRACCIÓN}

La inesperada revelación del art. 19 TUE como concreción del Estado de derecho, unida a las deficiencias de todas las herramientas concebidas para proteger los valores del art. 2 TUE, llevaron finalmente a la Comisión a activar el procedimiento de infracción directamente y sin subterfugios en el contexto poco habitual de la independencia judicial. Si nos centramos en el caso de Polonia, cabe señalar que la Comisión ha presentado hasta ahora tres recursos por incumplimiento contra este país y acaba de iniciar la fase administrativa de un cuarto procedimiento de infracción ${ }^{44}$.

Se trata, en primer lugar, del asunto C-619/18 Comisión/Polonia (Independencia del Tribunal Supremo) sobre la reducción de la edad de jubilación de los jueces del Tribunal Supremo y la potestad discrecional del presidente de la República para aprobar una prórroga, cuyo fallo representa una significativa aplicación de la doctrina de la independencia judicial contenida en el asunto Asociación Sindical de Jueces Portugueses, declarando por primera vez la incompatibilidad de una normativa nacional con el art. 19.1 TUE, párr. 2, y situando la independencia judicial en el centro del orden constitucional de la Unión $^{45}$.

Contrariamente a las conclusiones del abogado general Tanchev ${ }^{46}$, el TJUE no consideró necesario proceder a una evaluación de la aplicabilidad de la Carta en virtud de su art. 51(1), recordando que la protección judicial efectiva es un principio general, que el art. $47 \mathrm{CDF}$ solo ha reafirmado ${ }^{47}$. Por lo tanto, este fallo confirma que el único elemento que debe evaluarse para examinar la aplicabilidad del art. 19.1 TUE, párr. 2, es si un órgano jurisdiccional nacional puede ser llamado a pronunciarse sobre cuestiones relativas a la aplicación e interpretación del derecho de la Unión.

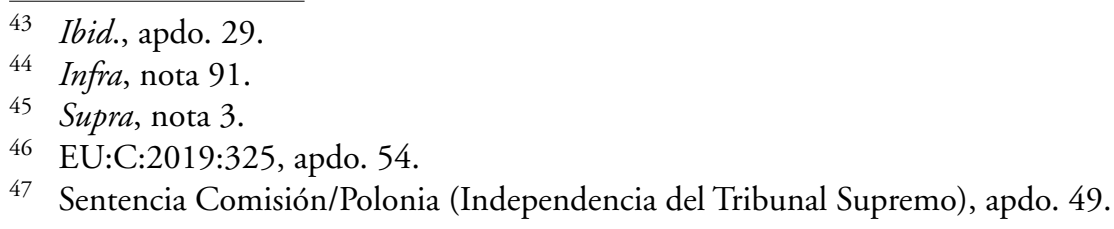


El TJUE reafirmó, asimismo, que la legitimidad de cualquier restricción a esta independencia debe estar sujeta a un escrutinio de su proporcionalidad, aunque parece ir más allá, considerándola como un valor casi absoluto, al estimar que las restricciones a las diferentes garantías de esta independencia, incluso si están justificadas y proporcionadas, no deben crear dudas sobre la impermeabilidad de un tribunal a factores externos y sobre su neutralidad con respecto a los intereses que tiene ante sí. El hecho de que el objetivo perseguido por la reducción de la edad de jubilación obligatoria no fuera legítimo fue suficiente para considerarla contraria a los Tratados, añadiendo que el efecto combinado de la reducción de la edad de jubilación, junto con la potestad discrecional otorgada al presidente de la República para aprobar una prórroga, daba la impresión de que perseguía excluir a un grupo específico de jueces del Tribunal Supremo ${ }^{48}$.

En el análisis de la segunda queja relativa a la discrecionalidad en la extensión del mandato de los jueces, el TJUE enfatizó que el procedimiento carecía de garantías suficientes para proteger a los jueces de la influencia política y disipar dudas sobre su independencia e imparcialidad, subrayando que las opiniones del Consejo Nacional del Poder Judicial (CNPJ) no estaban razonadas y eran irrecurribles, dejando caer de forma implícita la falta de independencia de este órgano frente a los poderes legislativo y ejecutivo ${ }^{49}$. El Tribunal concluyó que la discrecionalidad sin restricciones otorgada al presidente era capaz de crear dudas razonables en la mente de los justiciables en cuanto a la impermeabilidad de los jueces frente a factores externos ${ }^{50}$. Como último punto, el TJUE sintió la necesidad de defender la independencia de su propio proceso de nombramiento y renovación, rechazando, aunque con escasa contundencia, que fuera comparable con la ley polaca ${ }^{51}$.

En cuanto al segundo recurso por incumplimiento seguido en el asunto C-192/18 Comisión/Polonia (Independencia de los tribunales ordinarios), el Tribunal alcanzó conclusiones similares en relación con los tribunales ordinarios de este país ${ }^{52}$, añadiendo, además, un reproche sobre la discriminación entre jueces y juezas que representa la ley polaca al prever una edad distinta de jubilación para cada uno de estos dos colectivos.

\footnotetext{
Ibid., apdo. 85.

Ibid., apdos. 116-117.

Ibid., apdo. 118.

Ibid., apdo. 121-123.

52 Sentencia de 5 de noviembre de 2019, Comisión/Polonia (Independencia de los tribunales ordinarios), C-192/18, EU:C:2019:924.
} 
Finalmente, el tercer recurso por incumplimiento contra Polonia, presentado el 25 de octubre de 2019 y que se encuentra pendiente de resolución ${ }^{53}$, pretende combatir un nuevo régimen disciplinario que permite someter a los jueces de este país a investigaciones sobre el contenido de sus resoluciones, en particular aquellas que planteen cuestiones prejudiciales al TJUE, lo cual podría crear un efecto disuasorio totalmente inaceptable desde el punto de vista del respeto del principio de cooperación leal y del Estado de derecho ${ }^{54}$. El recurso aborda, además, la falta de independencia e imparcialidad de la Sala Disciplinaria del Tribunal Supremo, competente para ejercer el control de las resoluciones dictadas en los procedimientos disciplinarios frente a los jueces, habiendo accedido el TJUE a la suspensión cautelar solicitada por la Comisión de esta controvertida ley ${ }^{55}$. En el examen del fondo cabe esperar una nueva condena, especialmente a la vista de lo afirmado recientemente en el asunto Miasto Lowicz y Prokurator Generalny, en el que a pesar de declarar la inadmisibilidad de las cuestiones prejudiciales planteadas por varios tribunales polacos que solicitaban, en esencia, el examen de la conformidad del nuevo régimen disciplinario con el derecho de los justiciables a la tutela judicial efectiva, el TJUE no perdió la oportunidad para rechazar aquellas disposiciones nacionales que expongan a los jueces a procedimientos disciplinarios por haber planteado una petición de decisión prejudicial $^{56}$. Según el TJUE, la perspectiva de un procedimiento disciplinario podría impedir que aquellos ejerzan de manera efectiva la facultad de dirigirse al TJUE y sus funciones de jueces encargados de la aplicación del derecho de la Unión que les confieren los Tratados ${ }^{57}$.

\section{EL CONTROL JURISDICCIONAL HORIZONTAL}

La base jurídica del art. 19 TUE también revela su importancia en la segunda tipología de la jurisdiccionalización del control del Estado de

53 Asunto C-791/19, Comisión/Polonia, pendiente.

54 En el asunto C-564/19, Proceso penal contra IS; una jurisdicción húngara plantea al TJUE si el art. 267 TFUE se opone a que en un procedimiento de unificación de doctrina de una jurisdicción de última instancia pueda invalidar una remisión prejudicial realizada por una jurisdicción inferior y si el tribunal afectado debe ignorar dicha resolución.

55 Auto de 8 de abril de 2020, Comisión/Polonia, C-791/19 R, EU:C:2020:277.

56 Sentencia de 26 de marzo de 2020, Miasto Łowicz y Prokurator Generalny, C-558 y 563/18, EU:C:2020:234, apdo. 58.

57 Ibid., apdo. 59. 
derecho, es decir, la creación de una asociación de tribunales nacionales para la protección de este valor en estrecha colaboración con el TJUE.

El caso polaco es una vez más paradigmático. Solo dos semanas después del fallo del TJUE en el asunto Asociación Sindical de Jueces Portugueses, el Tribunal Superior de Irlanda planteó una cuestión prejudicial sobre la ejecución de una orden europea de detención (ODE) presentada por Polonia. Como se sabe, desde el asunto Aranyosi y Căldăraru ${ }^{58}$, el TJUE permite en circunstancias excepcionales limitaciones a los principios de confianza y reconocimiento mutuos para aplazar la ejecución de una ODE si existe en el Estado miembro de emisión un riesgo de trato inhumano o degradante, protegido por los arts. $4 \mathrm{CDF}$ y $3 \mathrm{CEDH}$. Y la misma doctrina ha mantenido en relación con el traslado de solicitantes de asilo ${ }^{59}$. Esta limitación dio lugar a la apertura de una brecha en la hasta entonces imperatividad del reconocimiento mutuo, planteando si el riesgo de conculcación, no ya de un derecho absoluto, sino relativo, como el derecho a un juicio justo, podría también justificar la inejecución del reconocimiento mutuo. Esta cuestión no tenía una respuesta sencilla, de una parte, por el citado carácter absoluto de la prohibición de penas o tratos inhumanos o degradantes, a diferencia de otros derechos fundamentales como puede ser el derecho a un proceso equitativo contemplado en el art. 47 de la Carta, el cual puede ser objeto de limitaciones $^{60} ; \mathrm{y}$, de otra, por el carácter excepcional de las circunstancias en las que, según el Dictamen del TJUE n. ${ }^{\circ}$ 2/13, deben admitirse limitaciones al principio de reconocimiento mutuo ${ }^{61}$.

Sin embargo, las preocupaciones ligadas a la independencia judicial llevaron al TJUE a dar una respuesta afirmativa a esta cuestión, admitiendo una nueva brecha en el reconocimiento mutuo al extender el ámbito de aplicación de las circunstancias excepcionales frente al riesgo de conculcación de un derecho relativo. Así, en el asunto Minister for Justice and Equality (LM), en el que el Tribunal Superior de Irlanda dudaba sobre si Polonia respetaría el derecho a un proceso equitativo en caso de que decidiera ejecutar una ODE hacia este país, el TJUE acepta extender el ámbito de aplicación de las circunstancias excepcionales frente al riesgo de conculcación del derecho a

58 Sentencia de 5 de abril de 2016, Aranyosi y Căldăraru, C-404 y 659/15 PPU, EU:C:2016:198.

59 Sentencias de 16 de febrero de 2017, C. K. y otros, C-578/16 PPU, EU:C:2017:127, apdo. 65; de 26 de julio de 2017, A.S., C-490/16, EU:C:2017:585, apdo. 41; y de 26 de julio de 2017, Jafari, C-646/16, EU:C:2017:586, apdo. 101.

60 Por ejemplo, Sentencia de 4 de junio de 2013, ZZ, C-300/11, EU:C:2013:363, apdo. 51.

61 Dictamen n. ${ }^{\circ}$ 2/13, apdo. 191. 
un tribunal independiente y, por tanto, al contenido esencial de este derecho fundamental.

Sin embargo, a pesar del particular contexto político-jurídico en el que se plantea la cuestión de la posible suspensión de esta ODE a Polonia, el Tribunal reafirmó criterios precisos para evaluar las circunstancias en las que la confianza mutua ya no es apropiada, conservando su carácter excepcional. Y ello porque mantuvo la obligación de que el tribunal de ejecución realice el examen en dos etapas prescrito en el asunto Aranyosi y Căldăraru, que incluye una evaluación abstracta del riesgo real de infracción del derecho fundamental a un proceso equitativo debido a deficiencias sistémicas o generalizadas en la protección proporcionada por el Estado miembro emisor, y, en segundo lugar, una evaluación concreta de la existencia de ese riesgo para el interesado. Solo si tras estos dos análisis persiste el riesgo de conculcación una autoridad judicial de ejecución podría abstenerse, con carácter excepcional, de dar curso a una ODE sobre la base del art. 1(3) de la Decisión Marco 2002/58462. A pesar de que este fallo constituye un notable desarrollo, es difícil imaginar cómo un acusado aún podría obtener un juicio justo en un país donde se socava sistemáticamente la independencia judicial, los jueces son intimidados por el Gobierno a través de investigaciones disciplinarias o penales si se atreven a plantear cuestiones prejudiciales y la revisión constitucional ha dejado de estar garantizada.

También en el marco de esta cooperación horizontal y utilizando la noción redescubierta de independencia judicial, la Sala de lo Social del Tribunal Supremo de Polonia planteó al TJUE una serie de cuestiones prejudiciales en el asunto A.K. y otros (Independencia de la Sala disciplinaria del Tribunal Supremo $)^{63}$ sobre si la recién creada Sala Disciplinaria de este mismo tribunal cumple los requisitos de la independencia judicial a la vista de sus vínculos con los poderes legislativo y ejecutivo; cuestión que también ha sido objeto de remisiones prejudiciales por varias jurisdicciones polacas ${ }^{64}$. En el fallo, la Gran Sala comenzó recordando que, según el art. 52(3) CDF, el principio de la independencia judicial debía definirse de acuerdo con la interpretación dada por el TEDH en su jurisprudencia relativa a los arts. 6 y $13 \mathrm{CEDH}$, de la que

62 Sentencia Minister for Justice and Equality (LM), apdo. 59.

63 Sentencia de 19 de noviembre de 2019, A.K. y otros (Independencia de la Sala disciplinaria del Tribunal Supremo), C-585, 624 y 625/18, EU:C:2019:982.

64 Véanse las cuestiones prejudiciales planteadas por el Tribunal Supremo de lo Contencioso-Administrativo de Polonia en el asunto C-824/18, A.B. y otros; y por la Sala disciplinaria del Colegio de Abogados de Varsovia en el asunto y C-55/20 Ministerstwo Sprawiedliwości, ambos pendientes. 
se deduce que el principio de protección judicial efectiva implica la independencia e imparcialidad de los tribunales y el respeto a la separación de poderes inherentes al Estado de derecho, en particular la ausencia de influencia directa o indirecta de los poderes ejecutivo o legislativo. Ciertamente, el TEDH no impone a los Estados parte un determinado modelo constitucional que regule las relaciones y la interacción entre los diferentes poderes estatales, siempre que sus opciones constitucionales no impidan la exigibilidad del respeto de las obligaciones derivadas del art. 6 del $\mathrm{CEDH}^{65}$. Sobre la base de esta doctrina, el TJUE proporcionó los elementos interpretativos destinados a guiar la evaluación que debía realizar el tribunal remitente. Sobre el nombramiento de los jueces de la Sala Disciplinaria por el presidente de la República, el Tribunal indicó los factores de los que podía deducirse su falta de independencia, en particular la ausencia de control judicial de los nombramientos propuestos por el CNPJ y la obligatoria inhibición de los tribunales ordinarios a favor de esta Sala en materia de derecho laboral ${ }^{66}$. Estas dudas, junto al hecho de que esta Sala solo pueda estar compuesta por magistrados recién elegidos con exclusión de los jueces que ya ejercen en el TS y el grado excepcional de autonomía que se le ha reconocido constituían indicaciones de un debilitamiento de su independencia y, de forma más general, la incompatibilidad de la ley polaca con los requisitos del art. 19 TUE, del art. 47 de la Carta, leído a la luz de la jurisprudencia del TEDH, aunque debía corresponder al tribunal remitente evaluar finalmente estas indicaciones.

Es probable que este fallo no haya cumplido las altas expectativas generadas, ya que no establece claramente si el CNPJ y la Sala Disciplinaria son o no independientes del Gobierno, contrastando con la solución adoptada en los fallos por incumplimiento precedentes, lo que podría explicarse por las diferentes funciones asignadas al Tribunal de Justicia en el marco de las demandas de petición prejudicial, por un lado, y en los procedimientos por infracción, por otro (Campos Sánchez-Bardona, 2020: 13). Es cierto, sin embargo, que proporciona importantes elementos de interpretación al juez a quo para ayudarlo en esta tarea $y$, al hacerlo, insinúa claramente que es poco probable que ambos órganos, tal como han sido concebidos, superen el examen de la independencia; máxime si este fallo se lee en conjunción con la sentencia previa por incumplimiento en el asunto C-619/18 Comisión/Polonia (Independencia del Tribunal Supremo).

65 Sentencia de 18 de octubre de 2018, Thiam c. Francia, n. ${ }^{\circ}$ 80018/12, CE:ECHR: 2018:1018JUD008001812, párr. 62.

66 Sentencia A.K. y otros (Independencia de la Sala disciplinaria del Tribunal Supremo), apdos. 143-144. 


\section{LA DEFENSA DEL ESTADO DE DERECHO DESDE ESTRASBURGO}

La actual crisis del Estado de derecho en Polonia y su controvertida reforma judicial aún no ha dado lugar a fallos del TEDH, aunque ya hay varias demandas presentadas. Así, en el asunto Xero Flor w. Polsce sp. z.o.o.I Polonia $^{67}$, la sociedad demandante alega que la composición de la Sala del Tribunal Constitucional que examinó su recurso era contraria al art. 6.1 $\mathrm{CEDH}$, dado que un determinado juez había sido elegido por la Cámara Baja del Parlamento en contra de una designación previa por el legislador anterior.

Por otra parte, los asuntos Broda y Bojara/Polonia ${ }^{68}$ se refieren de forma más directa a los cambios realizados en el sistema judicial polaco y, en particular, a la terminación prematura de los mandatos de los demandantes como presidente y vicepresidente del Tribunal Regional de Kielce. En su recurso invocan la infracción del art. 6.1 CEDH, al negárseles el derecho a un recurso jurisdiccional efectivo que les permitiera constatar el carácter arbitrario e irregular de su revocación.

Una problemática similar plantean los asuntos Grzęda/Polonia ${ }^{69}$ y Żurek/ Polonia $^{70}$ : la destitución prematura de los demandantes como miembros de pleno derecho del CNPJ, la cual se produjo ex lege, sin recibir ninguna notificación oficial y sin que se previera ningún recurso para impugnar su prematura destitución. Ambos recursos alegan la violación de los arts. 6.1 y $13 \mathrm{CEDH}$, al negárseles el acceso a un tribunal para impugnar sus ceses anticipados.

Todas estas demandas ya han sido comunicadas a Polonia y deberán ser resueltas por el TEDH en los próximos meses. Será entonces cuando tendrá la oportunidad de aplicar su doctrina relativa a la independencia judicial frente a las partes en el litigio y frente al poder ejecutivo, sobre la que ha insistido en su jurisprudencia desde hace más de treinta años. Cuando evalúa si un órgano judicial puede ser calificado como independiente, la jurisprudencia del TEDH se ha referido, principalmente, a cuatro criterios distintos: la forma de nombramiento de los jueces; la duración de sus mandatos; la existencia de ciertas garantías frente a presiones externas y si el tribunal presenta una apariencia de

67 TEDH, Xero Flor w. Polsce sp. z.o.o. / Polonia, n.o 4907/18, presentada el 3 de enero de 2018.

68 TEDH, Broda y Bojara / Polonia, n. ${ }^{\circ} 26691$ y 27367/18, presentadas, respectivamente, el 1 de junio y el 6 de abril de 2018 .

69 TEDH, Grzęda / Polonia, n. ${ }^{\circ}$ 43572/18, presentada el 4 de septiembre de 2018.

70 TEDH, Żurek / Polonia, n.o 39650/18, presentada el 6 de agosto de 2018. 
independencia ${ }^{71}$. También ha insistido el TEDH sobre la necesaria independencia del poder judicial frente al poder legislativo ${ }^{72}$.

Pero el principio de la independencia no trata solo de las relaciones con los poderes ejecutivo y legislativo, sino que comprende también la independencia dentro del propio sistema de administración de justicia. Los jueces individuales deben estar libres no solo de influencias externas, sino también internas, lo cual implica que no reciban directrices, ni presiones de sus colegas o de quienes ostentan responsabilidades administrativas dentro de un tribunal ${ }^{73}$. La simple ausencia de garantías suficientes que avalen esta independencia, en particular frente a sus superiores jerárquicos, puede llevar al TEDH a considerar objetivamente justificadas las dudas sobre la independencia e imparcialidad de un determinado tribunal ${ }^{74}$.

Es importante referirnos finalmente a la doctrina del TEDH sobre el tribunal predeterminado por la ley, garantía a la que se refieren explícitamente los arts. $6 \mathrm{CEDH}$ y $47 \mathrm{CDF}$. En su reciente fallo relativo a los jueces islandeses ${ }^{75}$, que algún autor ha calificado como equivalente en importancia al asunto Asociación sindical de jueces portugueses (Pech, 2020: 9), el TEDH sostuvo que constituía, en sí, una infracción del art. 6(1) CEDH la participación de un juez cuyo nombramiento se había efectuado infringiendo las normas nacionales relativas al procedimiento de nombramiento ${ }^{76}$. De confirmarse por la Gran Sala, esta doctrina representa toda una revolución al considerar que el

71 Sentencias del TEDH 25 de febrero de 1997, Findlay/Reino Unido, n. ${ }^{\circ}$ 22107/93, CE:ECHR:1997:0225JUD002210793; de 28 de junio de 1984, Campbell y Fell/ Reino Unido CE:ECHR:1984:0628JUD000781977, párr. 78; de 18 de julio de 2013, MaktoufyDamjanovic/BosniayHerzegovinan. ${ }^{\circ} 2312 / 08$ y34179/08, CE:ECHR:2013: 0718JUD000231208, párr. 49; de 3 de junio de 2005, Brudnicka y otros/Polonia n. ${ }^{\circ}$ 54723/00, CE:ECHR:2005:0303JUD005472300, párr. 38.

72 Sentencia del TEDH de 9 de diciembre de 1994, Refinerías griegas Stran y Stratis Andreadis/Grecia, CE:ECHR:1994:1209JUD001342787, \$ 49; Mastracci (2019).

73 Sentencias del TEDH de 22 de diciembre de 2009, Parlov-Tkalčič/Croacia, CE:ECHR:2009:1222JUD002481006, párr. 86; de 6 de octubre de 2011, Agrokompleks/Ucrania, CE:ECHR:2013:0725JUD002346503, párr. 137; y de 9 de octubre de 2008, Moïsseiev/Rusia, CE:ECHR:2008:1009JUD006293600, párr. 182.

74 Parlov-Tkalčič/Croacia, párr. 86, Agrokompleks/Ucrania, párr. 137, Moïsseiev/Rusia, párr. 184; y Sentencia de 10 de octubre de 2000, Daktaras/Lituania, CE:ECHR: 2000:1010JUD004209598, párrs. 36 y 38.

75 Sentencia del TEDH de 12 de marzo de 2019, Ástráðsson/Islandia, CE:ECHR: 2019:0312JUD002637418. El 9 de septiembre de 2019 este asunto fue referido a la Gran Sala del TEDH.

76 Ibid., párrs. 107, 108 y 123. 
derecho a ser juzgado por un tribunal establecido por ley en el sentido del art. 6(1) CEDH abarca, por su propia naturaleza, el procedimiento de nombramiento de los jueces.

En sus fallos frente a Polonia que ya hemos expuesto, el TJUE sigue de cerca toda esta doctrina, aunque ceñida a la independencia judicial, sin que haya tenido oportunidad de pronunciarse sobre el tribunal predeterminado por la ley para revisar exhaustivamente un procedimiento de nombramiento judicial, aunque varias cuestiones prejudiciales pendientes plantean precisamente este aspecto del proceso con todas las garantías ${ }^{77}$. Como precedente, contamos con su reciente fallo de 26 de marzo de 2020 en los asuntos Simpson y $H G^{78}$, donde se planteaban cuestiones relativas al procedimiento de nombramiento de los jueces del Tribunal de la Función Pública por el Consejo, la posibilidad de que el TG controle este nombramiento, si dicho control puede ser incidental, la ponderación de los diferentes principios que lo regulan y los efectos que una irregularidad en el nombramiento de un juez puede tener sobre los procedimientos judiciales en los que aquel haya participado. La principal aportación de este fallo es que aborda por primera vez el problema de cuándo una irregularidad cometida en el procedimiento de nombramiento de un tribunal es de tal naturaleza que implica una violación del art. 47(2) CDF. Antes de abordar este aspecto, el Tribunal trató la cuestión más técnica de si la legalidad de un nombramiento judicial puede revisarse de manera incidental. En este contexto, el TJUE interpretó el art. $47 \mathrm{CDF}$ en el sentido de que todo justiciable debe tener la posibilidad de denunciar esta violación. De ello resulta que el juez de la Unión debe poder verificar si una irregularidad que vicia el procedimiento de nombramiento ha podido entrañar la violación de ese

77 En los asuntos C-487/19, W.Ż. y C-508/19, Prokurator Krajowy el Tribunal Supremo polaco plantea la violación flagrante de la ley nacional al establecer un nuevo órgano jurisdiccional. Asimismo, en los asuntos C-764/19, C. S.A/Syndyk masy upadłości I.T. w O. w upadłości likwidacyjnej; C-763/19, D.S./SP, A.P, D.K., Sz. wK, varios órganos jurisdiccionales de Cracovia invitan al TJUE a señalar que no es un juez independiente con arreglo al derecho de la Unión una persona que haya sido nombrada para desempeñar el cargo de juez con flagrante infracción de las normas relativas al nombramiento de jueces. Por otra parte, en el asunto C-754/19, Prokuratura Rejonowa Warszawa - Wola w Warszawie/CU, un tribunal de Varsovia plantea las consecuencias de esta falta de independencia por infracción de las normas sobre nombramiento de jueces sobre las resoluciones dictadas en el marco de un procedimiento penal. Finalmente, en el asunto C-132/20, Getin Noble Bank, un juez de la Sala Civil del Tribunal Supremo pregunta por el estatus de los jueces nombrados a propuesta del CNPJ. 
derecho fundamental ${ }^{79}$, lo cual supone la creación de un nuevo recurso sobre la base del art. $47 \mathrm{CDF}$, siguiendo la innovadora interpretación de esta disposición del asunto Egenberger ${ }^{80}$. Otro aspecto innovador de este fallo se refiere a la cuestión de si un tribunal tiene la obligación de investigar la legalidad de los nombramientos judiciales. Para el Tribunal de Justicia, todo órgano jurisdiccional está obligado a verificar si, por su composición, es un tribunal que tiene dichas características cuando surja una duda fundada sobre este punto. Tal control constituye un requisito sustancial de forma cuya observancia es de orden público y debe, en consecuencia, ser examinado de oficio ${ }^{81}$. Se trata, sin duda, de otro desarrollo fundamental, dado que crea una obligación de control para los tribunales nacionales y cualquier legislación nacional que lo impida violaría claramente el art. $47 \mathrm{CDF}$. Finalmente, el Tribunal abordó la cuestión de cuándo esta irregularidad supone la infracción del art. 47(2) CDF, afirmando que se daría, en especial, cuando es de tal naturaleza y gravedad que cree un riesgo real de que otras ramas del poder, en particular el ejecutivo, puedan ejercer una indebida potestad discrecional que ponga en peligro la integridad del resultado al que conduce el proceso de nombramiento, originando así una duda legítima en el ánimo de los justiciables en cuanto a la independencia y la imparcialidad del juez o jueces afectados, lo cual sucede cuando se cuestionan normas fundamentales que forman parte integrante del establecimiento y del funcionamiento de ese sistema judicial ${ }^{82}$.

El examen de la reforma judicial polaca que debe desarrollar el TJUE debería probablemente comenzar por este examen del tribunal predeterminado por la ley y únicamente si supera este filtro, debería explorar la independencia (Paweł, 2020). La diferencia es que la prueba de la predeterminación por ley es más imparcial, sometiéndose a factores objetivos no directamente relacionados con un juez individual. De acuerdo con la jurisprudencia expuesta, bastaría encontrar una violación flagrante de la norma que crea el órgano jurisdiccional, con independencia de las circunstancias personales de cada juez, para estimar conculcado el derecho a un tribunal predeterminado por la ley. Por el contrario, la evaluación de la independencia, siguiendo las indicaciones del TJUE en el asunto A.K. y otros (Independencia de la Sala disciplinaria del Tribunal Supremo), es más subjetiva e individualizada, dando lugar a una verificación que tenga en cuenta consideraciones sobre el funcionamiento en la práctica de un tribunal y su apariencia ante la sociedad y ante los litigantes.

\footnotetext{
Ibid, apdo. 55 .

80 Sentencia de 17 de abril de 2018, Egenberger, C-414/16, EU:C:2018:257.

81 Sentencia Reexamen Simpson/Consejo y HG/Comisión, apdo. 57.

82 Ibid, apdo. 75.
} 
Tal evaluación es, por su propia naturaleza, más compleja y difícil, pudiendo eventualmente conducir a los responsables de esta verificación a opiniones diferentes frente a situaciones similares. Por el contrario, la exigencia de la predeterminación por ley es más objetiva, abarcando no solo la base jurídica de la existencia de un órgano jurisdiccional, sino también su composición en cada asunto ${ }^{83}$.

Podríamos entonces preguntarnos por qué en el asunto A.K. y otros (Independencia de la Sala disciplinaria del Tribunal Supremo) el TJUE limitó su examen al atributo de la independencia y no abarcó la predeterminación por ley de dicha Sala, sin atreverse a reformular las cuestiones como hace en otros asuntos. Y la respuesta probablemente sea que circunscribir dicho asunto a la independencia permite cierta flexibilidad y preserva el pluralismo constitucional (Krajewski y Ziółkowski, 2019), aunque pronto deberá afrontar dicho análisis ${ }^{84}$.

\section{LOS RESULTADOS}

Si finalmente atendemos al impacto real de todos estos fallos para revertir los perniciosos efectos sobre la independencia de los jueces en Polonia, podemos decir que el balance es relativo. Ya fue así en los asuntos húngaros relacionados, de una parte, con la reducción de la edad de jubilación forzosa de jueces, fiscales y notarios al cumplir 62 años de edad ${ }^{85}$, y de otra, con el supervisor de la protección de datos, cuyo mandato como autoridad independiente había sido interrumpido ${ }^{86}$. Los fallos condenatorios dictados por el TJUE solo permitieron revertir de forma muy parcial los efectos de aquellas perniciosas regulaciones debido fundamentalmente a la inevitable duración del procedimiento de infracción y al cumplimiento creativo que idearon las autoridades húngaras para sustraerse a estos fallos, generando múltiples críticas (Belavusau, 2013; Szente, 2017; Scheppele, 2015). Quedan por ver, sin embargo, los resultados frente a las nuevas leyes aprobadas por el Parlamento húngaro que brindan razones adicionales para la preocupación ${ }^{87}$.

83 Sentencias del TEDH de 28 de noviembre de 2002, Lavents/Letonia, CE:ECHR: 2002:1128JUD005844200, párrs. 82 y 114; de 9 de julio de 2009, Ilatovskiy/Rusia, CE:ECHR:2009:0709JUD000694504, párr. 36; y Ástráðsson/Islandia, párrs. 107, 108 y 123.

84 Supra, nota 77.

85 Supra, nota 9.

86 Ibid.

87 Supra, notas 39 y 40. 
Con respecto a Polonia, la situación es parcialmente distinta por cuanto la presión institucional europea está haciendo retroceder en parte al Gobierno de este país. Así ha ocurrido, por ejemplo, con la jubilación anticipada de un importante número de jueces, al modificar la Ley del Tribunal Supremo el 21 de noviembre de 2018, incluso antes del fallo final del TJUE de junio de 2019 en el asunto C-619/18 Comisión/Polonia (Independencia del Tribunal Supremo). En dicho resultado fue clave la aprobación de la medida cautelar de 19 de octubre de 2018 solicitada por la Comisión en el marco de dicho asunto $^{88}$ para exigir la suspensión de las disposiciones impugnadas, confirmada después por la Gran Sala ${ }^{89}$. El Tribunal demostró que había aprendido la lección de las controversias anteriores con Hungría, cuando el Gobierno de este país logró mantener la destitución generalizada de los jueces, a pesar de los fallos en contra del TJUE y del TEDH ${ }^{90}$. Esta experiencia parece que influyó claramente a la hora de sopesar los intereses a favor y en contra de la medida cautelar solicitada frente a Polonia, obligando al Gobierno polaco a retroceder y derogar la ley, lo cual permitió la reincorporación en sus cargos de 27 jueces del Tribunal Supremo que habían sido víctimas de la jubilación anticipada. Aunque pueda parecer una victoria pírrica porque estos jueces pronto alcanzarán la edad constitucional de jubilación, siendo reemplazados por jueces afines recomendados por el CNPJ, órgano carente de independencia, el precedente es de suma importancia porque el TJUE logró en un mes lo que Polonia se había negado a hacer durante los interminables debates con la Comisión. En este resultado influyó, sin duda, la velocidad con la que el TJUE aprobó la medida cautelar y el carácter demoledor de su aplicación. Si el Gobierno polaco hubiera intentado desplegar una estrategia de desacato a estos autos del TJUE se habría expuesto casi de inmediato a multas coercitivas potencialmente muy altas, como el TJUE ya nos enseñó en el asunto del bosque de Białowieza. Si en aquella ocasión se trató de una multa coercitiva de, al menos, 100000 euros/día y se trataba de la infracción de la Directiva Hábitats, lo más probable es que un asunto sobre una cuestión tan fundamental para el derecho de la Unión como la independencia judicial, su importe hubiese sido mucho más alto, equivaliendo en la práctica a retirar a este país una parte de

88 Auto de la vicepresidenta del TJUE de 19 de octubre de 2018, Comisión/Polonia, C-619/18 R, EU:C:2018:852.

89 Auto de 17 de diciembre de 2018, Comisión/Polonia, C-619/18 R, EU:C:2018:1021.

90 La reforma húngara fue impugnada ante el TEDH en el asunto Baka/Hungría, que dio lugar a la sentencia de 23 de junio de 2016, n.o 20261/12, CE:ECHR:2016: 0623JUD002026112. Este asunto fue presentado por el expresidente del Tribunal Supremo, confirmando el TEDH que la reforma promulgada a nivel constitucional infringía el $\mathrm{CEDH}$ porque no estaba sujeta a ninguna forma de revisión judicial. 
la financiación de los fondos de la Unión. Sin embargo, aunque los efectos de una multa impuesta por desobedecer un auto del TJUE son idénticos, sería probablemente percibida de manera diferente por la población en comparación con la reducción de la financiación de la política regional, un acto fácil de tergiversar por un Gobierno autocrático como una venganza motivada políticamente por una coalición de gobiernos extranjeros.

Al mismo tiempo, sin embargo, existe una escalada de la crisis del Estado de derecho en Polonia, al haber incrementado el Gobierno la presión política sobre los jueces. Así lo demuestra la entrada en vigor el pasado 14 de febrero de 2020 de una nueva ley, bautizada popularmente como "ley mordaza", que amplía la gama de faltas disciplinarias de los jueces obstinados y aumenta sus sanciones a fin de impedirles que cuestionen la independencia de otros tribunales ${ }^{91}$. A pesar de las opiniones negativas de todos los expertos que analizaron el proyecto ${ }^{92}$, fue aprobada a nivel parlamentario en un tiempo récord como reacción política a varios fallos de la Sala de lo Social del Tribunal Supremo dictados en ejecución de la sentencia del TJUE en el asunto A.K. y otros (Independencia de la Sala disciplinaria del Tribunal Supremo). Sobre la base de los factores establecidos por el TJUE para dirimir si un órgano jurisdiccional es independiente, esta Sala del TS polaco sostuvo que teniendo en cuenta los factores que dieron lugar a su creación, la extensión de sus competencias, su composición y la implicación del CNPJ en su constitución; la Sala Disciplinaria no podía considerarse ni imparcial, ni independiente de los poderes legislativo y ejecutivo, por lo que no podía continuar juzgando ${ }^{93}$. Por el contrario, otras salas de este mismo Tribunal han interpretado el fallo del TJUE en un sentido diferente. Así, la Sala de Control Extraordinario y Asuntos Públicos del TS dictó una sentencia el 8 de enero de 2020 en la que aplicando aparentemente la misma doctrina del TJUE, trató de limitar su alcance sobre la base de una relativización del principio de primacía y de una

91 El pasado 29 de abril de 2020 la Comisión inició la fase administrativa del procedimiento de infracción contra Polonia por esta nueva ley (https://bit.ly/3fNe6QP) al considerar que socava la independencia judicial de los jueces polacos y es incompatible con la primacía del derecho de la Unión.

92 Véanse las críticas de la Comisión de Venecia, Dictamen n.o 977/2019, de 16 de enero de 2020, CDL-PI(2020)002, https://www.venice.coe.int.; y de la OSCE, Urgent Interim Opinion on the Bill Amending the Act on the Organization of Common Courts, the Act on the Supreme Court and Certain Other Acts of Poland (as of 20 December 2019), https://www.osce.org/odihr/443731.

93 Sentencia de la Sala de lo Social del Tribunal Supremo de 5 de diciembre de 2019, A.K., PO 7/18. https://bit.ly/3fBz052. Además, otros dos fallos de 15 de enero de 2020 de esta misma Sala reiteran esta doctrina, III PO 8/18 y III PO 9/18. 
forzada identidad constitucional ${ }^{94}$, fallando que el examen de la independencia no era posible de oficio, sino únicamente a instancia de parte, además de decretar la imposibilidad de considerar carente de independencia al CNPJ ${ }^{95}$.

Para remediar esta discrepancia jurisprudencial, la presidenta del Tribunal Supremo que ejercía en ese momento convocó el 23 de enero de 2020 una reunión de las salas no afines al Gobierno (Civil, Penal y Social) que dictó una nueva resolución en la que reiteró que ni el CNPJ, ni los jueces elegidos por este órgano ni la Sala Disciplinaria eran suficientemente independientes de los poderes ejecutivo y legislativo ${ }^{96}$. Este nuevo fallo abría la puerta a cuestionar la independencia de cada juzgado o tribunal al frente de los cuales se encuentren jueces nombrados por el actual CNPJ y todas y cada una de sus resoluciones. Sin embargo, esta resolución fue apelada ante el Tribunal Constitucional, órgano que el pasado 20 de abril de 2020 procedió a anularla por considerar que constituía una inadmisible interferencia con la prerrogativa presidencial para nombrar jueces ${ }^{97}$.

El resultado de todo ello es que a pesar de su inconstitucional establecimiento y de los citados fallos, el CNPJ sigue funcionando con total normalidad como si nada hubiese ocurrido y continúa recomendando el nombramiento o la promoción de un gran número de jueces afines a la causa ${ }^{98}$. Del mismo modo, la Sala Disciplinaria del Tribunal Supremo continúa ejerciendo sus funciones jurisdiccionales, autoproclamándose como órgano judicial independiente. Sin embargo, la medida cautelar de suspensión de la ley polaca aprobada recientemente por el TJUE debería llevar a la inmediata suspensión de sus funciones ${ }^{99}$, enfrentándose en caso contrario a la posibilidad de que la Comisión proponga al TJUE la imposición de una multa coercitiva.

Finalmente, en cuanto a la ejecución de la sentencia prejudicial en el asunto Minister for Justice and Equality (LM), todo parece indicar que los jueces de instancia polacos ya no disfrutan de protección contra la presión política, por lo que será difícil que aquellos reconozcan que carecen de

94 Ignorando que el art. 4(2) TUE debe leerse a la luz de los arts. 2 y 6 TUE. Por consiguiente, las identidades nacionales deben respetarse siempre que sean compatibles con los valores fundacionales de la Unión, véase Faraguna (2017: 1639); Ziółkowski y Grabowska-Moroz (2019).

95 https://bit.ly/3fEe4dY.

96 https://bit.ly/3ebUwNu.

97 https://bit.ly/2YFSMFS

98 Su participación entusiasta en el intento de purga del Tribunal Supremo ha sido bien documentada tanto por la Comisión (https://bit.ly/2UWtSk3) como por la doctrina: véanse, entre otros, Pech y Wachowiec (2020).

99 Supra, nota 55. 
independencia en el marco del examen individual que debe desarrollar el juez de ejecución. En este sentido, el Tribunal Superior de Irlanda que planteó esta cuestión prejudicial remitió preguntas adicionales al tribunal polaco emisor de la ODE, confirmando la respuesta la inadecuación del análisis concreto exigido por el TJUE. Y ello porque fue redactada por el nuevo presidente del tribunal emisor recién designado por el actual ministro de Justicia, quien aseguró la independencia de todos los tribunales polacos ${ }^{100}$. Este no ha sido el caso, sin embargo, del Tribunal Superior del Lander alemán de Karlsruhe (Oberlandesgericht), que en un asunto fallado el pasado 17 de febrero de 2020 se negó a ejecutar una ODE emitida por Polonia debido a la falta de independencia de sus tribunales (Wójcik, 2020). Tras analizar toda la jurisprudencia relevante del TJUE, no solo el asunto Minister for Justice and Equality (LM) sino también los procedimientos de infracción contra Polonia, dedujo que el elemento fundamental de la independencia judicial debía ser la ausencia de presión política tanto en el nombramiento de los jueces como en el ejercicio de sus funciones. Fue en el examen concreto donde el Tribunal Superior de Karlsruhe innovó frente a fallos anteriores de otros tribunales, puesto que alcanzó la conclusión de que esta independencia ya no podía ser garantizada. De la misma forma, algunos tribunales de los Países Bajos también han expresado dudas recientemente sobre la certeza de un juicio justo en Polonia, suspendiendo varias decisiones de extradición hacia este país (Nielsen, 2018; Bárd y Morijn, 2020) ${ }^{101}$. La razón de este cambio jurisprudencial no ha sido otra que la entrada en vigor de la «ley mordaza» a mediados de febrero. En efecto, los cambios introducidos en Polonia con respecto a los procedimientos disciplinarios contra los jueces parecen justificar las dudas sobre la verdadera independencia del poder judicial, a lo que hay que añadir el fallo del TJUE en el asunto A.K. y otros (Independencia de la Sala disciplinaria del Tribunal Supremo), que aclaró los criterios para examinar esta independencia.

El balance de todo lo expuesto parece indicar que los resultados frente a las derivas autocráticas en algunos Estados son más difíciles de alcanzar a través de fallos prejudiciales si las autoridades nacionales afectadas deciden ignorarlos. En su jurisprudencia reciente, el Tribunal parece aceptar los límites del procedimiento prejudicial, dejando al juez a quo la cuestión de si

100 Este doble análisis ha dado lugar a bastantes críticas doctrinales, véanse, entre otros, Krajewski (2018: 805); Scheppele (2018) y las múltiples contribuciones al debate de Verfassungblog, «The CJEU's deficiencies judgment», https://bit.ly/3deHTzQ.

101 Se trata de dos fallos de 24 de marzo, ECLI:NL:RBAMS:2020:1896; ECLI:NL: RBAMS:2020:1931; y uno de 26 de marzo de 2020, ECLI:NL:RBAMS:2020:2008; del Rechtbank de Ámsterdam. 
las normas del derecho de la Unión se aplican al caso en cuestión ${ }^{102}$. Ciertas referencias preliminares implican un difícil equilibrio entre la prueba de su admisibilidad, de conformidad con el art. 267 TFUE, y el apoyo solicitado por el juez nacional, que se ve amenazado por medidas que limitan potencialmente su independencia y ponen en peligro el Estado de derecho ${ }^{103}$. Un ejemplo paradigmático sería el asunto Miasto Łowicz, al que ya hemos hecho referencia, donde el tribunal de remisión indicó que la introducción de un nuevo régimen disciplinario podía afectar a su capacidad de juzgar de manera independiente. Si bien la respuesta a las preguntas contenidas en la resolución de remisión podría no ser necesaria como tal para la resolución efectiva del litigio que tenía planteado ante sí, no puede negarse que los procedimientos disciplinarios contra miembros del poder judicial pueden influir potencialmente en el resultado de la sentencia del juez remitente por el temor a enfrentarse a un procedimiento disciplinario si el ministro de Justicia no está de acuerdo con su decisión. En otras palabras, las cuestiones abordaban claramente un tema de fundamental importancia sobre el respeto del Estado de derecho en un Estado miembro, que por definición afecta también al orden jurídico de la Unión. Sin embargo, la falta de conexión con el litigio planteado impide su admisibilidad. Por el contrario, los procedimientos de infracción acompañados de medidas cautelares de suspensión bajo apercibimiento de cuantiosas multas parecen ser extremadamente efectivos. Recordemos en este sentido que hasta ahora el TJUE ha dictado tres medidas cautelares de suspensión. La primera fue cuando las autoridades polacas desobedecieron abiertamente un auto anterior del Tribunal para detener la tala de árboles en el bosque de Białowieza. En un desarrollo sin precedentes, el Tribunal accedió a la solicitud de la Comisión de imponer el pago de multa de al menos 100000 euros por día de incumplimiento ${ }^{104}$ si Polonia no detenía esta práctica, a lo que accedió de inmediato. La segunda fue cuando las autoridades polacas intentaron reducir retroactivamente la edad de jubilación de los jueces del Tribunal Supremo en evidente violación de la Constitución polaca y del derecho de la Unión. El Tribunal ordenó la suspensión inmediata de la aplicación de esta legislación ${ }^{105}$, lo cual ocurrió de forma inmediata incluso antes de que el TJUE dictara su fallo en cuanto al fondo. Y la tercera medida cautelar acaba de ser impuesta, ordenando la suspensión inmediata de las actividades de la

102 Sentencia A.K. y otros (Independencia de la Sala disciplinaria del Tribunal Supremo), apdos. 132 y 140 .

103 Por ejemplo, Auto de 29 de enero de 2020, DŚ, C-522/18, EU:C:2020:42.

104 Supra, nota 27.

105 Supra, nota 87. 
sala disciplinaria del TS en lo que respecta a los asuntos disciplinarios relacionados con los jueces, desarrollo particularmente significativo en la medida en que esta Sala constituye uno de los principales instrumentos para subyugar a todos los jueces de este país, reservándose la Comisión la posibilidad de proponer al TJUE el pago de una multa si en el plazo de un mes el Gobierno polaco no respeta plenamente la suspensión ${ }^{106}$.

Cabe deducir de todo ello que la combinación de procedimientos acelerados de infracción con la adopción de medidas cautelares de suspensión bajo amenaza de cuantiosas multas ha demostrado ser una forma efectiva de reaccionar ante esta crisis del Estado de derecho. No obstante, para extremar sus resultados estos procedimientos de infracción no deberían limitarse a abordar cuestiones secundarias. En el caso específico de Polonia, un recurso debe atajar directamente, si el art. 19.1 TUE, párr. 2, lo permite, la pervivencia del CNPJ porque es el órgano clave en el proceso de demolición de la independencia judicial en este país ${ }^{107}$. Y mientras siga al frente de los nombramientos judiciales, la involución en el respeto de la independencia judicial se prolongará. Y algo similar debería ocurrir con el Tribunal Constitucional ${ }^{108}$, cuya falta de independencia fue bien documentada por la Comisión en su iniciativa de desencadenamiento del procedimiento del art. 7.1 TUE. Limitarse, por el contrario, a abordar exclusivamente algún aspecto secundario del sistema judicial polaco, como los poderes disciplinarios del ejecutivo frente al poder judicial, retrasará el proceso de remoción de los jueces inconvenientes, pero no evitará el acceso de nuevos jueces afines al sistema autocrático.

Mucho nos tememos, sin embargo, que el problema no es exclusivo de Polonia. En otros Estados miembros los jueces también son seleccionados por el poder ejecutivo ${ }^{109} \mathrm{y} / \mathrm{o}$ legislativo, creando una inaceptable dependencia hacia

106 Supra, nota 55.

107 Comisión de Venecia, Dictamen n. ${ }^{\circ}$ 977/2019, de 16 de enero de 2020, CDLPI(2020)002, https://www.venice.coe.int.

108 En el asunto C-547/19, Asociația Forumul Judecătorilor din România, el Tribunal Superior de Casación de Rumanía plantea si los arts. 2 y 19 TUE, apdo. 1, y el art. $47 \mathrm{CDF}$ se oponen a que el Tribunal Constitucional intervenga sobre el modo en que el Tribunal Supremo interpreta y aplica la normativa sobre la constitución de las formaciones judiciales.

109 En el asunto C-896/19, Repubblika/Il-Prim Ministru, una jurisdicción maltesa plantea directamente si los arts. 19 TUE, apdo. 1, y 47 CDF son contrarios a la facultad constitucional del primer ministro para nombrar jueces. Recordemos que en el asunto A.K. y otros (Independencia de la Sala disciplinaria del Tribunal Supremo), apdo. 133, el TJUE estableció que el mero hecho de que los jueces sean nombrados por el presidente de la República no es susceptible de crear una situación de dependencia, 
estos poderes, la cual es percibida por ellos mismos en proporciones preocupantes en países como España, Italia, Portugal y Bulgaria (Castillo Ortiz, 2017: 327). Quizás por ello debería estudiarse la posibilidad de establecer un estándar horizontal que requiera que los órganos que realizan estos nombramientos sean completamente independientes de los otros dos poderes, estando compuestos mayoritariamente por jueces ${ }^{110}$.

\section{EL RESPETO DEL ESTADO DE DERECHO POR LA PROPIA UNIÓN: ¿UNA CRITICABLE ASIMETRÍA?}

También frente a la propia Unión el Tribunal de Justicia trata de hacer prevalecer los distintos perfiles del Estado de derecho. Gracias al principio de Unión de derecho, en virtud del cual tanto las instituciones como los Estados miembros están sometidos al control de la conformidad de sus actos con los Tratados y los principios generales, en particular los derechos fundamentales ${ }^{111}$, y en el marco de sus competencias, el Tribunal trata de imponer el respeto por parte de las instituciones de sus elementos más tradicionales, intentando consolidar un enfoque equilibrado entre su poder discrecional y el control judicial (Von Danwitz, 2018).

Si entre los distintos perfiles de la Unión de derecho nos centramos en el control de legalidad de los particulares, el Tratado de Lisboa ha contribuido a remediar en gran medida las deficiencias estructurales identificadas con anterioridad al poner fin a la denominada estructura de pilares y relajar en cierta medida los requisitos establecidos en el art. 263 TFUE (Lenaerts, 2007). Sin embargo, incluso si dichos requisitos no parecen limitar la discreción del TJUE sobre cómo debe ejercer sus poderes de revisión, a lo largo de los años se puede identificar una tendencia general en su jurisprudencia para impulsar la resolución de los litigios planteados por los particulares a través de las cuestiones prejudiciales. Este enfoque descentralizado en el control

ni de suscitar dudas en cuanto a su imparcialidad, si una vez nombrados no están sometidos a presión alguna y no reciben instrucciones en el ejercicio de sus funciones. Sin embargo, ese aspecto, unido a otros factores, puede arrojar dudas sobre su impermeabilidad a influencias externas y, en consecuencia, sobre su genuina independencia.

${ }^{110}$ En este sentido se pronuncian el Dictamen n.o 10 (2007) del Consejo Europeo Consultivo de Jueces, https://rm.coe.int/168074779b, y la Recomendación del Comité de Ministros del Consejo de Europa, de 17 de noviembre de 2010, n.o CM/ $\operatorname{Rec}(2010) 12$, https://rm.coe.int/16807096c1.

111 Sentencias de 23 de abril de 1986, Los Verdes, 294/83, EU:C:1986:166, apdo. 23; y de 29 de junio de 2010, E y F, C-550/09, EU:C:2010:382, apdo. 44. 
de la legalidad es de alguna forma inconsistente con el alto nivel de uniformidad generalmente requerido en la aplicación de los actos del Derecho de la Unión, no pudiéndose descartar que pueda hacer peligrar en cierta medida la uniformidad de la Unión de derecho al tolerar y respaldar normas procesales internas dispares y, a veces, ineficaces. De otra parte, el principio de efectividad, durante mucho tiempo una creación jurisprudencial, está ahora consagrado en el segundo párrafo del art. 19 TUE, apdo. 1, transformándose drásticamente en una obligación de resultado para que los Estados miembros garanticen vías procesales efectivas. Pese a ello, no cabe descartar alguna deficiencia en la Unión de derecho derivada de la ausencia de recursos a nivel nacional. Al mismo tiempo, al entregar cada vez más asuntos a los tribunales nacionales, el TJUE está otorgando un alto grado de discrecionalidad a una gran cantidad de tribunales con diferentes agendas institucionales y probablemente también diferentes conocimientos del derecho de la Unión. La jurisprudencia reciente del TEDH demuestra que la complementariedad entre el recurso de anulación y la cuestión prejudicial como articuladora del derecho a un recurso jurisdiccional efectivo no siempre funciona adecuadamente $^{112}$. ¿Cuántas cuestiones prejudiciales han dejado de plantearse debido al abuso de la teoría del acto claro? ¿O cuántos recursos de anulación han sido declarados inadmisibles ya sea por la obstinación en interpretar de forma estricta las novedades que aportó el Tratado de Lisboa para relajar el control de legalidad de actos de alcance general ${ }^{113}$ o debido a los subterfugios jurídicos ideados para evitar este control?

El paradigma de estos subterfugios es, sin duda, el MEDE. Recordemos en este sentido el rechazo al control judicial centralizado de los memorandos de entendimiento en el marco de la crisis de la zona euro, dando lugar a una jurisprudencia decepcionante desde la perspectiva de las exigencias de la Unión de derecho (Kilpatrick, 2015; López Escudero, 2018). La inadmisibilidad del control de legalidad de las medidas del MEDE fue la regla durante algún tiempo, al considerar que los Estados miembros no aplican el derecho de

112 Sentencia del TEDH de 6 de diciembre de 2012, Michaud/Francia, n. ${ }^{\circ}$ 12323/11, ECHR:2012:1206JUD001232311; Decisión de 8 de abril de 2014, Dhahbi/Italia, n. ${ }^{\circ}$ 17120/09, ECHR:2014:0408JUD001712009; Decisión de 21 de julio de 2015, Schipani y otros/Italia, n. ${ }^{o}$ 38369/09, ECHR:2015:0721JUD003836909; Sentencia de 13 de febrero de 2020, Sanofi Pasteur/Francia, n. ${ }^{\circ}$ 25137/16,CE:ECHR:2020:02 13JUD002513716.

113 Véase, entre otras, Sentencia de 3 de octubre de 2013, Inuit Tapiriit Kanatami y otros, EU:C:2013:625. 
la Unión en el sentido del art. 51.1 CDF al instituir esta nueva organización ${ }^{114}$. Sin embargo, si para evitar las limitaciones de esta disposición en los asuntos contra Polonia el TJUE buscó y halló la concreción del valor Estado de derecho en el art. 19.1 TUE, no le sería imposible encontrar una vía similar que hiciera posible el control de legalidad de las medidas de ajuste económico de forma general, ya fuera teniendo en cuenta su verdadera naturaleza de actos de la Unión, dada la imbricación entre las medidas MEDE y las decisiones de coordinación económica del Consejo sobre control de los déficits públicos excesivos que incorporan las medidas de ajuste recogidas en los memorandos de entendimiento (Baraggia, 2016, López Escudero, 2018), o considerando que la inaplicabilidad de la Carta no debe impedir su control a través de la aplicación las tradiciones constitucionales comunes y/o los instrumentos internacionales sobre derechos humanos suscritos por todos los Estados miembros ${ }^{115}$. Pero lo que de ningún modo puede permitir esta interposición de organizaciones, totalmente controladas por los países de la zona euro, es impedir un control jurisdiccional adecuado. Recuérdese, en este sentido, la jurisprudencia del TEDH en virtud de la cual cuando los Estados parte transfieren algunas competencias a una organización, están obligados a que los derechos garantizados por el Convenio reciban dentro de esa organización una protección equivalente a la ofrecida por el mecanismo convencional ${ }^{116}$. Rechazar el examen de estos asuntos supone endosar la posible responsabilidad a los Estados miembros según el art. 61 de la CDI sobre la responsabilidad de las organizaciones internacionales relativo a la elusión de obligaciones de un Estado miembro de una organización ${ }^{117}$ con el consiguiente riesgo de jurisprudencias contradictorias a la que puede dar lugar el control descentralizado. Es cierto, sin embargo, que el TJUE ha intentado mitigar en parte esta falta de protección judicial efectiva admitiendo la posibilidad de reclamar la responsabilidad extracontractual de las instituciones que participan en la elaboración de

114 Sentencia de 27 de noviembre de 2012, Pringle, C-370/12, EU:C:2012:756, apdos. 180 y 181.

$115 \mathrm{Y}$ ello incluso si tras emprender esta vía y admitir estos asuntos el Tribunal pudiera alcanzar la conclusión de que las medidas de ajuste son compatibles con los derechos fundamentales, como ha venido haciendo el TEDH en relación con el CEDH, reconociendo un amplio margen de apreciación a los Estados parte, TEDH, Austerity measures, https://bit.ly/2YNybiY.

116 Decisión del TEDH, de 12 de mayo de 2009, Gasparini/Italia y Bélgica, n. ${ }^{\circ}$ 10750/03, ECHR:2009:0512DEC001075003; Sentencia de 16 de marzo de 1998, Waite y Kennedy/Alemania, n. ${ }^{\circ}$ 26083/94, ECHR:1999:0218JUD002608394.

117 Artículos de la CDI sobre la responsabilidad de las organizaciones internacionales, doc. A/66/10, p. 172. 
estos memorandos. El fallo del TJUE en el asunto Ledra Advertising ${ }^{118}$ o del TG en el asunto Steinhoff $y$ otros $/ B C E^{119}$ contribuyen a preservar de forma general los derechos fundamentales bajo la nueva gobernanza económica europea, dejando atrás el enfoque puramente economicista de los rescates desarrollados durante décadas bajo la égida del FMI; eliminan la ambigüedad de la naturaleza jurídica de los memorandos de entendimiento y los correspondientes programas de ajuste económico ${ }^{120}$ y sus relaciones con la CDF; y clarifican los deberes jurídicos de las instituciones cuando toman parte en la asistencia financiera a los Estados miembros de la eurozona. Si observamos más detenidamente, sin embargo, se trata solo de una victoria pírrica por la dificultad en demostrar la existencia de una violación suficientemente caracterizada de una norma que tenga por objeto conferir derechos a los particulares. Si bien el derecho de propiedad puede resultar afectado por la mayoría de las medidas de condicionalidad, la necesidad de demostrar nada menos que una intervención desmesurada e intolerable que lesione la propia esencia de ese derecho condenará al rechazo la gran mayoría de recursos que sigan esta vía ${ }^{121}$.

En otros ámbitos, el balance a día de hoy es aún más decepcionante. Así ocurre con el control de las competencias externas de la Unión, en particular, en materia de inmigración. La paulatina utilización de actos atípicos para los acuerdos de readmisión, la Declaración UE-Turquía concluida en forma de acuerdo ejecutivo, incluso si no abarca exclusivamente cuestiones técnicas (Gatti, 2016); los partenariados de movilidad ${ }^{122}$; o la proliferación de instrumentos financieros de emergencia y herramientas extrapresupuestarias tienen consecuencias negativas para la unidad e integridad del presupuesto de la

118 Sentencia de 20 de septiembre de 2016, Ledra Advertising y otros, C-8 a 10/15, EU:C:2016:701.

119 Sentencia de 23 de mayo de 2019, Steinhoff y otros/BCE, T-107/17, EU:T:2019:353.

${ }^{120}$ Reglamento (UE) n. ${ }^{\circ} 472 / 2013$ del Parlamento Europeo y del Consejo, de 21 de mayo de 2013, sobre el reforzamiento de la supervisión económica y presupuestaria de los Estados miembros de la zona del euro cuya estabilidad financiera experimenta o corre el riesgo de experimentar graves dificultades, DO n. ${ }^{\circ} \mathrm{L} 140$, de 27 de mayo de 2013.

121 Véanse en este sentido las sentencias del Tribunal General de 13 de julio de 2018, Chrysostomides, K. \& Co. y otros/Consejo y otros, T-680/13, EU:T:2018:486; de 24 de enero de 2017, Nausicaa Anadyomène y Banque d'escompte/BCE, T-749/15, EU:T:2017: 21; y de 7 de octubre de 2015, Accorinti y otros/BCE, T-79/13, EU:T:2015:756.

122 Concluidos, entre otros, con Moldavia y Cabo Verde en 2008, Georgia en 2009, Armenia en 2011, Marruecos, Azerbaiyán y Túnez en 2013, Jordania en 2014 y Bielorrusia en 2016, véase COM (2017) 0471 final, de 6 de septiembre de 2017; García Andrade (2018). 
Unión y, lo que es peor, ponen en duda el respeto del principio democrático al no requerir la aprobación del Parlamento, pese a estar prevista su participación en los Tratados. Es llamativo, sin embargo, el clamoroso silencio de esta institución, a pesar de esta grave desviación del marco legislativo y financiero, echándose en falta aquella Eurocámara que promovió en el pasado algunos de los más célebres fallos de la jurisprudencia del Tribunal de Justicia. En lugar de articular recursos por la violación de sus prerrogativas, el Parlamento se limita a adoptar insípidas resoluciones que solo recuerdan la necesidad genérica de respetar los derechos fundamentales en la acción exterior de la Unión. Esta pasividad es muy perjudicial para el control del respeto de la Unión de derecho, ya que estos actos externos atípicos difícilmente pueden ser objeto de un recurso de anulación por los particulares debido a las restrictivas condiciones de admisibilidad. Y cuando el Tribunal pudo pronunciarse, por ejemplo, sobre la Declaración UE-Turquía, declinó hacerlo bajo extrañas argumentaciones. Así ocurrió en el asunto N.F.Consejo Europeo, en el que tres solicitantes de asilo de nacionalidad afgana y paquistaní pedían su anulación por temor a que, en ejecución de este acuerdo, Turquía los devolviera a sus países de origen, donde eran perseguidos y atacados. En primera instancia pudimos leer cosas tan extrañas como que el acuerdo, incluso si versaba sobre competencias en parte comunitarias y a pesar de gestionarse su firma en el marco del Consejo Europeo ${ }^{123}$, no había sido concluido por esta institución, sino por los jefes de Estado y de Gobierno, mientras que en casación el recurso fue considerado manifiestamente inadmisible por inconsistente ${ }^{124}$, al limitarse a realizar afirmaciones genéricas sobre el fallo en primera instancia. Sin embargo, gracias al magnífico sitio web curia.eu todos pudimos leer los argumentos alegados por los demandantes, sin que se dedujera en ningún caso esta inconsistencia. Una nueva emboscada al Estado de derecho (Andrés Sáenz de Santa María, 2018: 156) que escapa al control judicial merced a un exagerado formalismo nada compatible con las garantías derivadas del derecho a un recurso jurisdiccional efectivo, como el TEDH ha manifestado recientemente ${ }^{125}$. Y es que cualquier transformación de los acuerdos internacionales de hard a soft ni puede ni debe conducir a un desprecio total de los principios fundamentales que subyacen en la relación entre la Unión, sus instituciones,

123 Auto del Tribunal General de 28 de febrero de 2017, N.F./Consejo Europeo, T-192/16, EU:T:2017:128, apdos. 61-70.

124 Auto de 12 de septiembre de 2018, N.F., N.G. y N.M./Consejo Europeo, C-208 a 210/17 P, EU:C:2018:705, apdo. 16.

125 Sentencia del TEDH, de 31 de marzo de 2020, Dos Santos Calado y otros / Portugal, n. ${ }^{\circ}$ 55997/14 y 68143/16 78841/16, CE:ECHR:2020:0331JUD005599714. 
los Estados miembros y sus ciudadanos (Wessel, 2020: 11). Mientras que ello siga ocurriendo no cabe duda de que existe un contraste entre el control del respeto del Estado de derecho por parte de la propia Unión y la actitud opuesta frente a sus Estados miembros.

\section{CONCLUSIONES}

La realidad de los últimos años ha demostrado un creciente número de casos en los que algunos Gobiernos buscan conscientemente socavar sistemáticamente los valores clave de la Unión. Es entonces cuando nos hemos dado cuenta de las insuficiencias del art. 7 TUE para abordar los desafíos sistémicos percibidos en esos Estados miembros, derivadas fundamentalmente de la discrecionalidad involucrada en este procedimiento y, en especial, la falta de verdadero coraje político. Todo ello está permitiendo no solo un desafortunado impasse en el Consejo, sino también una cierta resistencia burocrática frente a la Comisión y al Parlamento en todo lo relacionado con el respeto de este valor de la Unión. Basándose en una singular interpretación de los principios de atribución y de equilibrio institucional, el Consejo defiende el carácter de lex specialis del art. 7 TUE, siendo el único mecanismo disponible en virtud de los Tratados para hacer cumplir los valores del art. 2 TUE. Sin embargo, desde finales de 2017 una serie de fallos fundamentales han revelado la firme voluntad del TJUE para actuar como guardián de la ortodoxia del orden constitucional europeo. La inesperada revelación del art. 19 TUE como concreción del Estado de derecho ha llevado por fin a la Comisión a activar varios procedimientos de infracción y a las jurisdicciones nacionales a plantear cuestiones prejudiciales basados directamente y sin subterfugios en el contexto poco habitual de la independencia judicial. Sin embargo, el impacto real de todos estos fallos para revertir los perniciosos efectos sobre la independencia de los jueces en ciertos Estados miembros es solo relativo. Difícilmente podemos esperar resultados frente a las derivas autocráticas en algunos Estados miembros si las autoridades nacionales afectadas deciden ignorar los fallos prejudiciales del TJUE. Por el contrario, los procedimientos acelerados de infracción acompañados de medidas cautelares de suspensión bajo apercibimiento de cuantiosas multas han demostrado ser una forma efectiva de reaccionar ante esta crisis del Estado de derecho. No obstante, para extremar sus resultados estos procedimientos no deben limitarse a abordar cuestiones secundarias. En el caso específico de Polonia, un recurso debe atajar directamente el problema que representa la pervivencia del CNPJ porque es el órgano clave en el proceso de demolición de la independencia judicial en este país. Y algo similar debería ocurrir con el Tribunal Constitucional, cuya 
falta de independencia ha sido bien documentada. Y la doctrina del TEDH sobre el tribunal predeterminado por la ley, que los arts. 47 CDF y 6(1) $\mathrm{CEDH}$ indican como primera garantía de un juicio justo, tal vez ayude en este sentido. Limitarse, por el contrario, a abordar algún aspecto secundario del sistema judicial polaco, como los poderes disciplinarios del Ejecutivo frente al poder judicial, retrasará el proceso de remoción de los jueces inconvenientes, pero no evitará el acceso de nuevos jueces afines al sistema autocrático. Mucho nos tememos, sin embargo, que el problema no es exclusivo de Polonia. En otros Estados miembros los jueces también son seleccionados por el poder ejecutivo y/o legislativo, creando una inaceptable sumisión a estos poderes, la cual es percibida por ellos mismos en proporciones preocupantes en varios Estados miembros. Por ello, quizás sería conveniente establecer un estándar horizontal que requiera que los órganos que nombran a los jueces sean completamente independientes de los otros dos poderes.

También frente a la propia Unión el Tribunal de Justicia trata de hacer prevalecer los distintos perfiles del Estado de derecho, imponiendo el respeto de sus elementos más tradicionales por parte de las instituciones. Sin embargo, en algunos ámbitos el balance es solo tenue. Cabe destacar en este sentido que la complementariedad entre el recurso de anulación y la cuestión prejudicial como articuladora del derecho a un recurso jurisdiccional efectivo no siempre funciona adecuadamente. De la misma forma, el balance es también decepcionante en el ejercicio del control de las competencias externas de la Unión en materia de inmigración. Cualquier transformación de los acuerdos internacionales de hard a soft ni puede ni debe conducir a un desprecio total de los principios fundamentales que subyacen en la relación entre la Unión, sus instituciones, los Estados miembros y sus ciudadanos. Mientras que ello siga ocurriendo no cabe duda de que existe un contraste entre el control del respeto del Estado de derecho por parte de la propia Unión y la actitud opuesta frente a sus Estados miembros.

\section{Bibliografía}

Adamski, D. (2019). The social contract of democratic backsliding in the 'new EU' countries. Common Market Law Review, 56 (3), 623-666.

Andrés Sáenz de Santamaría, P. (2018). El Estado de derecho en el sistema institucional de la Unión Europea: Realidades y desafíos. En D.J. Liñán Nogueras y P. Martín Rodríguez (dirs.). Estado de derecho y Unión Europea (pp. 129-156). Madrid: Tecnos.

Avbelj, M. (2013). The Inherent Limits of Law: the Case of Slovenia. Verfassungsblog: On Matters Constitutional [blog], 6-12-2013. Disponible en: https://bit. ly/30Li2wZ. 
Baraggia, A. (2016). Conditionality through the lens of the CJEU: a "blurry" vie. Verfassungsblog: On Matters Constitutional [blog], 30-6-2016. Disponible en: http://dx.doi.org/10.17176/20160701-094108.

Baratta, R. (2016). Rule of Law 'Dialogues' Within the EU: A Legal Assessment. Hague Journal on the Rule of Law, 8 (2), 357-372. Disponible en: https://doi. org/10.1007/s40803-016-0032-z.

Bárd, P. (2017). The Open Society and Its Enemies: An attack against CEU, academic freedom and the rule of law. CEPS Policy Insights, 14. Disponible en: https:// bit.ly/3flp3J0.

Bárd, P. y Morijn, J. (2020). Domestic Courts Pushing for a Workable Test to Protect the Rule of Law in the EU: Decoding the Amsterdam and Karlsruhe Courts' post-LM Rulings (Part II). Verfassungsblog: On Matters Constitutional [blog], 19-4-2020. Disponible en: https://bit.ly/2UNGN7M.

Bárd, P. y Śledzińska-Simon, A. (2019). Rule of law infringement procedures. A proposal to extend the EU's rule of law toolbox. CEPS paper in liberty and security in Europe, 9. Disponible en: https://bit.ly/3d6sB03.

Belavusau, U. (2013). On age discrimination and beating dead dogs: Commission v. Hungary, Common Market Law Review, 50 (4), 1145-1160.

Besselink, L. (2017). The Bite, the Bark and the Howl: Article 7 TEU and the Rule of Law Initiatives. En J. Jakab y D. Kochenov (eds), The Enforcement of EU Law and Values: Ensuring Member States' Compliance (pp. 128 y ss.). Oxford: Oxford University Press. Disponible en: https://doi.org/10.1093/acprof:oso/9780198746560.003.0009.

Blázquez Peinado, M.D. (2019). La UE ante las vulneraciones del Estado de Derecho por parte del Estado polaco: panorámica general y estado actual de la cuestión. Revista General de Derecho Europeo, 48, 14-57.

Bonelli, M. y Claes, M. (2018). Judicial Serendipity: How Portuguese Judges Came to the Rescue of the Polish Judiciary. European Constitutional Law Review, 14, 622-643. Disponible en: https://doi.org/10.1017/S1574019618000330.

Butler, I. (2018). How to safeguard European values through the Multiannual Financial Framework: Two proposals. Disponible en: https://bit.ly/3hw1y1C.

Campos Sánchez-Bardona, M. (2020). La protección de la independencia judicial en el Derecho de la Unión Europea. Revista de Derecho Comunitario Europeo, 65, 11-31. Disponible en: https://doi.org/10.18042/cepc/rdce.65.01.

Castillo Ortiz, P. J. (2017). Councils of the Judiciary and Judges' Perceptions of Respect to Their Independence in Europe. Hague Journal of the Rule of Law, 9, 315-336. Disponible en: https://doi.org/10.1007/s40803-017-0061-2.

Dawson, M., Muir, E. y Claes, M. (2014). A Tool-box for legal and Political Mobilisation in European Equality Law. En D. Anagnostou (ed.). Rights and Courts in Pursuit of Social Change. Legal Mobilisation in the Multi-Level European System (pp. 105-128). Oxford: Oxford University Press.

De la Rosa, S. (2019). La 'sanction budgétaire' risque-t-elle de faillir? À propos du règlement portant protection du budget européen en cas de défaillance de l'État de droit. Revue des affaires europeennes, 1, 67-74. 
Di Federico, G. (2015). The Protection and Promotion of the Rule of Law in the European Union: State of the Art, Criticalities and Future Perspectives. The Turkish Yearbook of International Relations, 46, 1-22. Disponible en: https://doi. org/10.1501/Intrel_0000000299.

Editorial (2015). Safeguarding EU values in the Member States: Is something finally happening? Common Market Law Review, 52 (3), 619-628.

Editorial (2016). The Rule of Law in the Union, the Rule of Union Law and the Rule of Law by the Union: Three interrelated problems. Common Market Law Revision, 53, 597-606.

Faraguna, P. (2017). Constitutional Identity in the EU - A Shield or a Sword?. German Law Journal, 18 (7), 1617-1640. Disponible en: https://doi.org/10.1017/ S207183220002246X.

Fisicaro, M. (2019). Rule of Law Conditionality in EU Funds: The Value of Money in the Crisis of European Values. European Papers, 4 (3), 695-722.

García Andrade, P. (2018). EU External Competences in the Field of Migration: How to Act Externally When Thinking Internally. Common Market Law Review, 55 (1), 157-200.

Gatti, M. (2016). The EU-Turkey Statement: A Treaty That Violates Democracy. EJIL: Talk! [blog], 18-4-2016. Disponible en: https://bit.ly/3frwiiA.

Gormley, L. W. (2017). Infringement Proceedings. En A. Jakab y D. Kochenov (eds.). The Enforcement of EU Law and Values: Methods against Defiance (pp. 65-78). Oxford: Oxford University Press. Disponible en: https://doi.org/10.1093/ acprof:oso/9780198746560.003.0005.

Halmai, G. (2017). Legally sophisticated authoritarians: the Hungarian Lex CEU. Verfassungsblog: On Matters Constitutional [blog], 31-3-2017. Disponible en: https://dx.doi.org/10.17176/20170401-102552.

- (2018). The possibility and desirability of economic sanction: Rule of law conditionality requirements against illiberal EU Member States. EUI working paper law, 6. Disponible en: https://doi.org/10.2139/ssrn.3126231.

Heinemann, F. (2018). Going for the wallet? Rule-of-law conditionality in the next EU multiannual financial framework. Review of European Economic Policy, 53 (6), 297-301. Disponible en: https://doi.org/10.1007/s10272-018-0771-2.

Hillion, C. (2016). Overseeing the Rule of Law in the EU: Legal Mandate and Means. En C. Closa y D. Kochenov (eds.). Reinforcing Rule of Law Oversight in the European Union (pp. 59-81). Cambridge: Cambridge University Press. Disponible en: https://doi.org/10.1017/CBO9781316258774.005.

Kelemen, R. D. y Scheppele, K. L. (2018). How to stop funding autocracy in the EU. Verfassungsblog: On Matters Constitutional [blog], 1-9-2018. Disponible en: https://doi.org/10.17176/20180910-094901-0.

Kilpatrick, C. (2015). On the Rule of Law and Economic Emergency: The Degradation of Basic Legal Values in Europe's Bailouts. Oxford Journal of Legal Studies, 35 (2), 1-29, Disponible en: https://doi.org/10.1093/ojls/gqv002. 
Kochenov, D. (2015). EU Law without the rule of law: Is the veneration of autonomy worth it? Yearbook of European Law, 34, 74-96. Disponible en: https:// doi.org/10.1093/yel/yev009.

- (2017). The Acquis and lts Principles. The Enforcement of the 'Law' versus the Enforcement of 'Values in the EU. En A. Jakab y D. Kochenov (eds.). The Enforcement of EU Law and Values (pp. 9-27). Oxford: Oxford University Press. Disponible en: https://doi.org/10.1093/acprof:oso/9780198746560.003.0002.

Kochenov, D. y Pech, L. (2015). Monitoring and Enforcement of the Rule of Law in the EU: Rhetoric and Reality. European Constitutional Law Review, 11(3), 512-540. Disponible en: https://doi.org/10.1017/S1574019615000358.

- (2016). Better Late than Never? On the European Comission's Rule of Law Framework and its First Activation. Journal of Common Market Studies, 54(5), 1062-1074. Disponible en: https://doi.org/10.1111/jcms.12401.

Krajewski, M. (2018). Who is afraid of the European Council? The Court of Justice's cautious approach to the independence of domestic judges. European Constitutional Law Review, 14(4), 792-813. Disponible en: https://doi.org/10.1017/ S1574019618000457.

Krajewski, M. y Ziółkowski, M. (2019). The Power of 'Appearances', Verfassungsblog: On Matters Constitutional [blog], 26-11-2019. Disponible en: https://bit. ly/2UNK5bv.

Lazzerini, N. (2016). Less is more? Qualche rilievo sulla legittimità e sul merito delle recenti iniziative delle istituzioni europee in materia di salvaguardia dei valori fondanti dell'Unione. Rivista di Diritto Internazionale, 99(2), 514-523.

Lenaerts, K. (2007). The Rule of Law and the Coherence of the Judicial System of the European Union. Common Market Law Review, 44(6), 1625-1659.

Levits, E. (2018). L'Union européenne en tant que communauté des valeurs partagées - les conséquences juridiques des articles 2 et 7 du traité sur l'Union européenne pour les États membres. En Liber Amicorum Antonio Tizzano. De la Cour CECA à la Cour de l'Union: le long parcours de la justice européenn (pp. 509-522). Torino: Giappichelli.

Liñán Nogueras, D. J. (2018). La internacionalización del Estado de Derecho y la Unión Europea: una traslación categorial imperfecta. En D. J. Liñán Nogueras y P. Martín Rodríguez (dirs.). Estado de derecho y Unión Europea (pp. 39-68). Madrid: Tecnos. Disponible en: https://doi.org/10.2307/j.ctvh1dj5b.6.

López Escudero, M. (2018). La degradación de las exigencias del Estado de Derecho en el ámbito de la Unión económica y monetaria. En D.J. Liñán Nogueras y P. Martín Rodríguez (dirs.): Estado de derecho y Unión Europea (pp. 189-229). Madrid: Tecnos. Disponible en: https://doi.org/10.2307/j.ctvr33bnv.15.

Mastracci, M. (2019). Judicial Independence: European Standards, ECtHR Criteria and the Reshuffling Plan of the Judiciary Bodies in Poland. Athens Journal of Law, 5(3), 323-350. Disponible en: https://doi.org/10.30958/ajl.5-3-6.

Müller, J. W. (2015). Should the EU protect democracy and the rule of law inside Member States? European Law Journal, 21(2),141-160. Disponible en: https:// doi.org/10.1111/eulj.12124. 
Nicolosi, S. (2015). The contribution of the Court of Justice to the codification of the founding values of the European Union. Revista Derecho Comunitario Europeo, 51, 613-643. Disponible en: https://doi.org/10.18042/cepc/rdce.51.05.

Nielsen, N. (2018). Dutch refuse Polish arrest warrant over judicial fears. Euobserver, 5-10-2018. Disponible en: https://euobserver.com/justice/143034.

Oliver, P. y Stefanelli, J. (2016). Strengthening the Rule of Law in the EU: The Council's Inaction. Journal of Common Market Studies, 54(5), 1075-1084. Disponible en: https://doi.org/10.1111/jcms.12402.

Pawel, F. (2020). Only a Court Established by Law Can Be an Independent Court: The ECJ's Independence Test as an Incomplete Tool to Assess the Lawfulness of Domestic Courts. Verfassungsblog: On Matters Constitutional [blog], 23-1-2020. Disponible en: https://intr2dok.vifa-recht.de/receive/mir_mods_00008092.

Pech, L. (2020). Dealing with 'fake judges' under EU Law: Poland as a Case Study in light of the Court of Justice's ruling of 26 March 2020 in Simpson and HG. Reconnect, Working Paper, 8. Disponible en: https://bit.ly/2zGhEF2.

Pech, L. y Wachowiec, P. (2020). 1460 Days Later: Rule of Law in Poland R.I.P. (Part II). Verfassungsblog: On Matters Constitutional [blog], 15-1-2020. Disponible en: https://doi.org/10.17176/20200120-125954-0.

Pech, L. et al. (2019). The European Parliament Sidelined: On the Council's distorted reading of Article 7(1) TEU. Verfassungsblog: On Matters Constitutional [blog], 8-12-2019. Disponible en: https://doi.org/10.17176/20191209-060505-0.

Pérez Bernárdez, C. (2019). A new Rule of Law Mechanism for the European Union Budget: An effective negative conditionality for the respect of EU's fundamental values? En L. M. Hinojosa y P. J. Martín González (dirs.). La regulación internacional de los mercados y la erosión del modelo politico y social europeo (pp. 263-302). Cizur Menor: Thompson Reuters-Aranzadi.

Rangel de Mesquita, M. J. (2018). European Union Values, Rule of Law and the Multiannual Financial Framework 2021-2027: The Commission's Proposal to Protect the EU Budget against Threats to the Rule of Law. ERA Forum, 19(2), 287-294. Disponible en: https://doi.org/10.1007/s12027-018-0523-6.

Sadurski, W. (2009). Adding Bite to the Bark: The Story of Article 7, EU Enlargement, and Jörg Haider. Columbia Journal of European Law, 16, 385-426.

Scheppele, K. L. (2015). Understanding Hungary's Constitutional Revolution. En A. Von Bogdandy y P. Sonnevend (eds.). Constitutional Crisis in the European Constitutional Area: Theory, Law and Politics in Hungary and Romania (pp. 111-124). London: Hart. Disponible en: https://doi.org/10.5771/9783845261386-124.

- (2016). Enforcing the basic principles of EU law through systemic infringement actions. En C. Closa y D. Kochenov (eds.). Reinforcing Rule of Law Oversight in the European Union (pp. 105-132). Cambridge: Cambridge University Press. Disponible en: https://doi.org/10.1017/CBO9781316258774.007.

- (2018). Rule of Law Retail and Rule of Law Wholesale: The ECJ's (Alarming) Celmer Decision. Verfassungsblog: On Matters Constitutional [blog], 28-7-2018. Disponible en: https://doi.org/10.17176/20180730-095958-0. 
Scheppele, K. L. et al. (2018). Never Missing an Opportunity to Miss an Opportunity: The Council Legal Service Opinion on the Commission's EU Budget-Related Rule of Law mechanism. Verfassungsblog: On Matters Constitutional [blog], 12-11-2018. Disponible en: https://doi.org/10.17176/20181115-215538-0.

Schmidt, M. y Bogdanowicz, P. (2018). The infringement procedure in the rule of law crisis: How to make effective use of Article 258 TFEU. Common Market Law Review, 55(4), 1061-1100.

Steinbeis, M. (2017). The hand on the faucet. Verfassungsblog: On Matters Constitutional[blog], 3-6-2017. Disponible en: https://dx.doi.org/10.17176/20170603091619.

Szente, Z. (2017). Challenging the Basic Values: Problems in the Rule of Law in Hungary and the Failure of the EU to Tackle Them. En A. Jakab y D. Kochenov (eds.). The Enforcement of EU Law and Values: Ensuring Member States' Compliance (pp. 456-475). Oxford: Oxford University Press. Disponible en: https://doi. org/10.1093/acprof:oso/9780198746560.003.0027.

Uitz, R. (2019). The perils of defending the rule of law through dialogue. European Constitutional Law Review, 15(1), 1-16. Disponible en: https://doi. org/10.1017/S1574019619000051.

Vita, V. (2018). Research for REGI Committee: Conditionalitiesin Cohesion Policy. Bruselas: European Parliament. Disponible en: https://bit.ly/3frvnhX.

Von Bogdandy, A. (2019). Principles and Challenges of a European Doctrine of Systemic Deficiencies. Max Planck Institute for Comparative Public Law \& International Law Research Paper, 14. Disponible en: https://doi.org/10.2139/ ssrn.3431303.

Von Danwitz, T. (2018). Values and the Rule of Law: Foundations of the European Union - An Inside Perspective from the ECJ. Potchefstroom Electronic Law Journal, 21, 1-17. Disponible en: https://doi.org/10.17159/1727-3781/2018/ v21i0a4792.

Wessel, R. (2020). Normative transformations in EU external relations: the phenomenon of 'soft' international agreements. West European Politics, 1-21. Disponible en: https://doi.org/10.1080/01402382.2020.1738094.

Wójcik, A. (2020). Muzzle Law leads German court to refuse extradition of a Pole to Poland under the European Arrest Warrant. Disponible en: https://bit.ly/2BgYDsX.

Ziółkowski, M. y Grabowska-Moroz, B. (2019). Enforcement of EU Values and the Tyranny of National Identity: Polish Examples and Excuses. Verfassungsblog: On Matters Constitutional [blog], 26-11-2019. Disponible en: https:/doi. org/10.17176/20191127-002325-0. 
